\title{
Searching for Influential Actors in Co-Offending Networks: The Recruiter
}

\author{
Ashley Englefield ${ }^{1}$, Barak Ariel ${ }^{2}$ \\ ${ }^{1}$ Cantab. Institute of Criminology, University of Cambridge, Sidgwick Avenue Cambridge CB3 9DA, UK \\ ${ }^{2}$ Lecturer in Experimental Criminology, Institute of Criminology, University of Cambridge, Sidgwick Avenue \\ Cambridge CB3 9DA, UK \\ Correspondence: Barak Ariel, Lecturer in Experimental Criminology, Institute of Criminology, University of \\ Cambridge, Sidgwick Avenue Cambridge CB3 9DA, UK, and Assistant Professor, Institute of Criminology, Faculty of \\ Law, Hebrew University, Mount Scopus, Jerusalem 91905, Israel.
}

\author{
Received: March 8, 2017 \\ Accepted: April 6, 2017 \\ Available online: April 12, 2017 \\ doi:10.11114/ijsss.v5i5.2351 \\ URL: https://doi.org/10.11114/ijsss.v5i5.2351
}

\begin{abstract}
The co-offending literature research has recently unraveled the possible existence of a specific class of offender commonly referred to as a "recruiter": one who recruits others who are younger or less experienced for the purpose of offending. Yet the available evidence has focused on small or non-representative samples, and has supplied a limited conceptual scope for explaining how instigation takes place within co-offending groups. We provide evidence from population-level arrest records over eight years in Sacramento, California $(n=80,245$ offenders). Social network analysis is used to study how "crime ideas" are transmitted. We identified 1,092 recruiters, yet this subgroup is responsible for $6 \%$ of arrests in Sacramento and a disproportionate number of younger and less experienced recruits. The data suggest a pattern of recruitment specialization in specific crime categories and wider age differentials in against-persons rather than property crime categories. We contextualize the findings within Dawkin's (1976) meme theory as a conceptual framework for explaining how recruitment takes place, why "crime ideas" can be seen as units of imitation, and under which conditions they are subsequently replicated, reproduced, and evolve. Directions for future research are then considered, with an emphasis on crime control initiatives.
\end{abstract}

Keywords: recruitment, social networks, co-offending, meme theory

\section{Introduction}

For many years, sociologists of crime have recognized that criminal behavior is likely to occur in groups of two or more (Andresen and Felson, 2012; Breckinridge and Abbott, 1912; Cohen, 1955; McCord and Conway, 2002; Shaw and McKay, 1942; Piquero, Farrington, and Blumstein, 2003; Reiss, 1986, 1988; Reiss and Farrington, 1991; Shaw and Moore, 1931; van Mastrigt and Farrington, 2011; Warr, 1996, 2002). This is perhaps unsurprising, as human beings are social animals who tend to act in clusters and within various community networks. The type of behavior - criminal or otherwise - undoubtedly shapes the form and size of the group (McGloin and Thomas, 2016a, 2016b; see also Weerman, 2014 and McGloin and Piquero, 2010), yet there is little disagreement among scholars about the importance of peer influence, interaction rituals, and the existence of social networks, on the likelihood that a specific behavior would take place (Akers, Krohn, Lanza-Kaduce, and Radosevich, 1979; Goffman, 1967). While the interaction between psychological, social, and biological factors are wide and complex, delinquency — much like any other endeavor-is by and large affected by having another person or persons to "do it" with (Morin, 2011; see also Moffitt, 1993). This claim is so overarching in criminology that McGloin and Nguyen (2012:464) went on to conclude that "the stack of empirical studies addressing peer influence on delinquency comprises one of the largest and most developed domains of criminological literature."

Despite this large body of work on accomplice networks, there is a growing, yet thin layer, of research on the specific and actual patterns of co-offending (Kennedy, 2009). Only very recently have we started to unravel what specific contexts and social processes antecede group-based criminal behavior (McGloin and Rowan, 2015), and frankly, our knowledge base is still in its infancy. Criminal and delinquent networks research in general, and co-offending more explicitly, is primarily descriptive in nature (Erickson, 1971), localized (Zimring, 1981), or crime-specific (Carrington, 
2002; Lantz and Hutchison, 2015; Piquero, Farrington, and Blumstein, 2007; Reiss and Farrington, 1991; van Mastrigt, 2008). It remains unclear how these groups are formed, in which circumstances they are sustained, and what sets them apart from "solo" criminal activity.

One line of research that has attracted some attention is the mechanism by which people are "brought into" these cooffending groups. Certain individuals introduce or propagate ideas to commit crime, and they are referred to as "recruiters" (Reiss, 1986, 1988; Reiss and Farrington, 1991; van Mastrigt and Farrington, 2011), "instigators" (McGloin and Nguyen, 2012), "experienced offenders" (Warr, 1996), "solicitors" (Gottfredson and Hirschi, 1990), "seekers of suitable co-offenders" (Tremblay, 1993), "Typhoid Marys" (Sherman, 1992), and so on. It is of particular interest for scholars as well as practitioners to identify who instigates criminal activity and how people are persuaded to "do" what is otherwise immoral, hurtful, and illegal behavior.

Furthermore, the literature is not clear whether recruiters are responsible for more crime or more harmful crimes than non-recruiters. It is also unclear whether recruitment into co-offending creates more harmful offenders ( $c f$. Metcalfe and Baker, 2014). What we do know, however, is that the amount of evidence on co-offending suggests that there is a greater likelihood that co-offending is associated with a criminal career (Andresen and Felson, 2011; McAndrew, 2000) and "criminogenic lifestyles" (Mcgloin and Nguyen, 2012:484) - which by itself could indicate how important these recruiters are for our broader understanding of criminal behavior. If some individuals cause others to enter a life of crime, and because of that mentorship the recruits are likely to become persistent offenders, then they are a great source of concern. Alternatively, it could be that persistent criminal activity is primarily opportunistic and that co-offending happens stochastically, rather than through a recruitment process. Falsifying our assumption that these recruiters are indeed important in the study of criminal behavior in groups is equally important, as it would require us to channel our focus onto other key actors in the group (Weerman, 2003).

More critically, despite the growing body of research on recruiters, the literature is longer on evidence but shorter on theory. As recently noted by van Mastrigt and Farrington (2011:329), "focused theoretical work on co-offending in general and recruitment in particular, is regrettably in short supply." Who are these recruiters? How do criminal "ideas" spread from crime mentors to their "supervisees"? Which broader conceptual frameworks can illustrate, with the necessary precision, this process of enrollment and/or instigation? This is a rather difficult question, because cooffending patterns, group dynamics, and peer-influences represent a multifaceted and complex social phenomenon. Except for Warr (1996), Weerman (2003), and more recently McGloin and Rowan (2015), a robust theoretical framework for recruitment is absent, and the present paper aims to fill this void.

In addition, except for van Mastrigt and Farrington (2011) and Sarnecki (2001), the available evidence is nonrandom and highly localized (e.g., McGloin and Nguyen, 2012), and often specific to particular crime categories (e.g., Lantz and Hutchison, 2015). There has also been a greater focus on crimes committed by groups of minors (e.g., Cohen, 1955), whereas we should focus on both juveniles and adults. We know little about how recruitment varies across crime types and across offenders, or what the scope of recruitment is in large samples ( $c f$. Carrington, 2009; Sarnecki, 2001). For instance, McGloin and Nguyen (2012) were the first to lay out more fundamentally the circumstances in which instigation takes place, following a dearth of research on this issue - but even that seminal paper was limited in scope and generalizability, given its data sources (discussed below).

Thus, the available theoretical exposition on recruiters has been generally crude. One recent development has been the use of social network analysis procedures to understand co-offending and recruitments more specifically (Lantz and Hutinson, 2015; McGloin, 1995; McGloin and Kirk, 2010; Sarnecki, 2001; Rostami and Mondani, 2015). The focus on networks is relatively novel in criminology (Wasserman and Faust, 1997:20), but concentrating on the limited number of actors and the relations among the actors within the unique delinquent networks has attracted a great deal of scholastic interest (Lyons, 2011; Wasserman and Faust, 1994). The ability to illustrate how "crime ideas" are transmitted within a network of offenders enables scholars in various fields to develop a conceptual explanation of criminal recruitment.

In this paper, we applied these techniques to a population level dataset of both juvenile and adult arrestees in the city of Sacramento over a period of eight consecutive years. We searched for influential nodes within networks of co-arrestees in the form of recruiters. Based on official arrest records (notwithstanding their limitations, which we address later), we explored the links between these recruiters and their recruits. Of a population of 80,245 individuals who were involved in 128,629 unique criminal cases, we identified 1,092 offenders who fit the definition afforded by previous scholars of "recruiters" and 4,157 "recruits." We then looked specifically at their characteristics and what sets them apart from solo offenders.

When discussing results, we turn to "meme theory" as a robust theoretical framework to best describe the process of recruitment in criminal behavior, and possibly co-offending more broadly. Meme, first introduced by Richard Dawkins 
(1976), comfortably explains how criminogenic ideas "can pass between people—as replicators and differential survivors that resemble genes, albeit evolving and adapting in a very different medium. In the crime context, examples of memes are criminal values and subcultures, methods of offending, or of prevention, and the requisite designs, tools, and equipment developed by either side" (Ekblom, 1999:30). The theory of memes is suitable here and complements Sherman's (1992) idea of recruitment as 'crime ideas' that "spread like diseases" because the Dawkins' approach illustrates that crime, like genes, can evolve through replication, mutation, and selection. We will then defend the argument that criminal ideas reproduce through memes, whereas the effectiveness of crime control measures against criminal groups can be explained in such terms as well-and that carries tremendous implications. First, however, we review the available body of work on recruitment and co-offending more broadly, before turning to our study in Sacramento, California.

\subsection{Literature Review}

The literature on co-offending is substantial (Conway and McCord, 2002; McGloin et al., 2008; van Mastrigt and Farrington, 2011; Carrington, 2002, 2009; Piquero, Farrington and Blumstein, 2007; Reiss and Farrington, 1991; van Mastrigt, 2008). Although the term itself was coined by Reiss (1980) only 30 years ago, many of the early, $20^{\text {th }}$ century crime scholars have considered co-offending to one extent or another (e.g., Cloward and Ohlin, 1960; Cohen, 1955; Shaw and McKay, 1942; Shaw and Moore, 1931; Sutherland, 1947). Some studies point to opportunist co-offending patterns (Lantz and Hutchison, 2015; McGloin et al., 2008; Warr, 1996; see also Nagin, Lum, and Solow, 2015), while others have found that crime committed in groups is in fact more profound than solo careerists (McGloin and Piquero, 2010; Felson, 2009). Co-offending groups can vary in size, ranging from three members (Reiss, 1988; Walsh, 1986) to many dozens - as in the case of gangs, "crime-by-association," and organized crime (Klein and Crawford, 1967; Weerman, 2003). The degree of stability can also range quite dramatically, with some co-offenders committing crime together for many years (for social capital in co-offending, see McCarthy and Hagan, 2001), while other co-offending formations are sustained for relatively short durations, often for the purpose of committing just one crime together (McGloin et al., 2008).

What does seem to unify co-offending groups and set them apart from solo criminals is a process of association with other co-offenders or prospective co-offenders (Erikson, 1971; Sutherland, 1947). This is particularly the case with cooffenders where one "partner" is inexperienced or a first-timer. Social exchange theory (see Weerman, 2003) suggests that joint offending is an interpersonal exchange of material and immaterial goods, in which each offender has something to gain from the cooperation of the other. In this respect, a criminal network is defined as one that ends with a criminal behavior, but all behaviors start with an idea - which Sutherland (1947), Bandura (1977), and Akers et al. (1979) have all contextualized as a learning process, coupled with differential association. The association with other offenders with the aim of committing a crime must include not only a technical teaching on how to commit the crime (Conway and McCord, 2002; McGloin and Piquero, 2009), but also provide the justification, rationalization, or normative affirmation that the crime should be committed (Blumenthal et al., 1972; Katz, 2008; Matza, 1964). For this reason, the conditions in which this process of association takes place, that is, how "crime ideas" are transmitted within the group, is of great interest to crime scholars (see review in Sarnecki, 2001).

Within these co-offending networks, learning processes, and group dynamics, we find the specialized case of recruitment. The late $\mathrm{Al}$ Reiss (1988) acknowledged that some offenders are indeed responsible for prompting group offending, whereas other offenders follow coconspirators into crime. As McGloin and Nguyen (2011:17) suggested, "there are conceptual reasons to believe that some individuals, who are, older than their less experienced accomplices, high rate offenders, and who rotate through several accomplice groups, and those who are systematically more prone to instigate group crime." It is particularly the case with less experienced or young offenders because of the psychosocial dynamics of this type of interaction: someone must motivate, instigate, and lead an individual into committing the crime. Regardless of the criminal network's size, the type of "job" that is offered to the younger or less experienced offender, and irrespective of the risks involved (Alarid, Velmer, and Hochstetler, 2009; McCarthy, Hagan, and Cohen, 1998), a particular person must have "supported" the other person in taking part in the co-offending activity. Recruitment, like co-offending in general, is an instrumental process (Tremblay, 1993). Beyond inspiring young(er) offenders to commit the crime, there are technical lessons to be taught when committing crime. In these respects, the imitation, reproduction, and recruitment processes are similar to any supervisor-supervisee relationship (on imitations more broadly, see Meltzoff and Gopnik, 1993; Tomasello et al., 1993). It is these types of offending individualsrecruiters and recruits - that we are most interested in.

By definition, each offender in this social exchange has something to gain from the cooperation of the other. Recruiters benefit from the practical assistance and/or praise of their protégés, and in exchange provide them with information, skills, and/or appreciation (Weerman, 2003). However, in the recruitment patterns of co-offending, this mutual benefit goes beyond "just" the exchange of interests: there is an inherent learning process. Both Akers (1988) and Sutherland 
(1947) would undoubtedly argue that recruitment may be an important mechanism through which criminal definitions, skills, and rationalizations are transmitted from more experienced to less-experienced offenders in criminal networks. Therefore, involvement with recruiter co-offenders early in one's criminal career may provide particularly powerful learning opportunities, in which one can directly observe and imitate the behaviors and values of more experienced teacher accomplices (see review in van Mastrigt and Farrington, 2011). For example, criminal behavior is learned particularly through interactions with other individuals in a process of communication; the principal part of the learning of criminal behavior occurs within intimate personal groups. When criminal behavior is taught, the teaching includes both the techniques of committing the crime, which are sometimes very complicated, and the specific direction of motives, drives, rationalizations, and attitudes. There is an inherent operant principle involved in these dynamics, with a tangible modeling process of positive and negative reinforcements that characterize these exchanges (Akers, 1988). The recruit becomes delinquent because of an "excess of definitions favorable to violation of the law over definitions unfavorable to violation of the law" (Sutherland, 1947:6-7). This type of differential association may vary in frequency, duration, priority, and intensity, but generally speaking, the process of learning criminal behavior by association with criminals through mentors would be more successful than through trial and error.

Social psychologists and sociologists should feel comfortable with these ideas, given their interest in social interactions between unequal peers. For instance, Tarde (1903) defended the view that people adopt new behaviors and attitudes through symbolic interactions, where "ideas precede imitation of their expression" (p.207). For imitation to take place, people must first "perceive a person's attitudes and behavior as salient, internalize the pattern and, especially, the meanings attached to the act, and then 'decide' whether the action fits with their own value-orientations, cherished norms, and self-interest" (Abrutyn and Mueller, 2014:701). We learn from particular individuals to which we are anchored, predominantly from those who we come to consider significant others (Aron and McLaughlin-Volpe, 2001; Shneidman, 1993). This learning process occurs when ideas are "appropriated through interaction and evaluated based on the exposed person's own social psychological disposition...even those 'imposed' from superiors involve a cognitive, moral/aesthetic, and/or affectual dimension" (Abrutyn and Muller, 2014:702).

It should therefore become immediately clear why learning, imitation, and persuasion through a crime-mentorship relationship is more powerful than "simple" co-offending (Henry and Einstadte, 1988:235): criminogenic ideas are more likely to survive under these conditions. It has been repeatedly shown that recruitment relationships can shape the recruits' subsequent criminal careers (Andresen and Felson, 2011; McAndrew, 2000; McGloin and Nguyen, 2012; Morselli et al., 2006). There also seems to be a greater likelihood for "criminogenic lifestyles" following recruitment (Mcgloin and Nguyen, 2012:484). Drawing again from learning theories, if indeed the mentor is idolized and his or her ideas are internalized as legitimate, then a life of crime is more likely to persist (Moffitt, 1993). The recruiter becomes a significant other (Akers, 2011; Alarid, Burton, and Cullen, 2000; Horney, Osgood, and Marshall, 1995)—which again makes these recruiters particularly interesting for understanding how crime develops over time (see Grasmick and Bursik, 1990).

Perhaps one of the most celebrated evidence on recruitment within the framework of co-offending was first detected in a longitudinal study of 411 boys as they progressed from age 8 to age 32 (Reiss and Farrington, 1991). The study revealed individuals who "bring in" individuals into criminal activity. Recruiters were nominally defined in this study as individuals who do not have the same criminal partner over time and who are responsible for introducing individuals to a pattern of repeated criminal behavior. Reiss and Farrington (1991) suggested that since rates of offending among individual networks varied, a prolific or higher rate offender who is also predisposed to co-offend would need to move across networks to find and recruit accomplices. The criterion for being labeled as such was that the prolific offender chose a less-experienced co-offender and, by this process, 6 of the 411 participants were identified as recruitersroughly $1 \%$ of the sample.

Warr's (1996) important contribution to the recruitment literature suggests that while high-frequency offenders were more likely to be recruiters, there is no mutual exclusiveness in recruitment patterns. This suggests that recruiters recruit, but they are also recruited by others. Therefore, Warr (1996) concludes that there is "more" to recruitment than psychological attributes, such as ecological and opportunistic qualities as well. As we turn to explain how crime is transmitted in networks in Sacramento, this piece of evidence will become particularly important.

In, 2011, van Mastrigt and Farrington obtained data from a metropolitan area in the north of England with a population of approximately 1.3 million. The data covered a span of time between March, 2002 and February, 2005. While Reiss and Farrington (1991) looked at recruitment as an addendum to a larger study on delinquency, Farrington and van Mastrigt (2011) explored the relationship between recruits and recruiters as a primary focus of research, with a large sample ( $\mathrm{n}=61,646)$. Recruiters were operationally defined as (a) "prolific offenders," having 10 or more offenses in the study period of 36 months; (b) top-quartile offenders in terms of the number of co-offenders - at least 5; and (c) at least $51 \%$ of their accomplices were younger than themselves. Applying these criteria, $0.01 \%$ of the sample $(n=86)$ were 
identified as recruiters (Farrington and van Mastrigt, 2011).

McGloin and Nguyen (2012) looked at co-offending instigations in Colorado correctional facilities. They found that, of a group of 498 individuals, $13 \%$ of the offenders instigated others to commit crimes. Interestingly, skills, rather than trust, were found to be the prominent reason for instigating others (on the importance of expertise, see Hochstetler, 2001). McGloin and Nguyen (2012) further showed that the recruits, or "followers," were usually low-rate offenders, whereas the recruiters were usually prolific and "serious" offenders. To a large extent, this dichotomy, whether it actually exists, resembles Moffitt's (1993) seminal taxonomy of life-course persistent and adolescence limited offenders: the former have a long-lasting and persistent offending pattern, whereas for the latter, the frequency dramatically changes - ten times more offending in the teen years and then it virtually disappears over time. More importantly, Moffitt (1993) suggests that life-course persistent offenders - recruiters - often have neuropsychological problems with a criminogenic environment, including pathological personalities, while adolescence-limited offendersrecruits - are characterized by poor mental development, susceptible to peer pressure, and motivated to mimic offending behavior. While Moffitt (1993) does not explicitly talk about recruits, adolescence-limited offenders may, in an attempt to address the maturity gap, be susceptible to influence from life-course persistent co-offenders (p.688). Thus, Moffitt (1993), McGloin and Nguyen (2012), and van Mastrigt and Farrington (2011) lend support to the hypothesis that recruiters and non-recruiters' individual and offending characteristics may differ in notable ways (e.g., recruiters might be expected to be older, more versatile, and more committed offenders).

Finally, in the latest study that looked at recruiters, Lantz and Hutchison (2015) observed a list of adult offenders convicted of burglary and criminal trespassing offenses in Centre County, Pennsylvania (2001-2010). They reported that in most co-offender groups, at least one offender is identifiably important and central. These are recruiters "through whom the other members are connected" (p.681). This study, coupled by a conclusion reached by Reiss (1998) fifteen years earlier, is particularly informative given the policy implications that resonate from the authors' conclusions: "if we could identify high-rate offenders who recruited many persons into committing delinquent acts or who had a substantial effect on the individual crime rates of numerous offenders, then these offender recruiters might be targeted for special treatment" (p.119). It is not clear whether this conclusion can be materialized under controlled settings, as Lantz and Hutchison (2015) never tested this conclusion within an experimental framework (for weaknesses of non-experimental designs, see Sherman et al., 1998), yet it does suggest that there may be important practical implications for looking at these offenders at the network level, beyond specific deterrence purposes (see Braga and Weisburd, 2011).

\subsection{The Present Research: Sacramento}

As summarized by Lantz and Hutchison (2015:662), "research has largely supported the idea that a small number of cooffenders assume important roles as "recruiters." These influential nodes in the criminal network are "real," and the scholarly work presented above is indicative of the growing importance that researchers have attached to this subgroup of offenders. However, despite the major contribution of the studies that dealt with co-offenders and recruiters, there are several questions that remain unanswered because previous work has analyzed limited samples, not entire populations. This issue was already alluded to by Reiss (1988), who has noted that small sample sizes make it challenging to differentiate the types of crime and ages of the offenders - and, as the most recent literature on co-offenders has observed, specific types of co-offending networks (Sarnecki, 2001). For instance, while van Mastrigt and Farrington (2011) determined how many in their sample fit the recruiter profile, they were unable to show whether they are linked to a disproportionate number of co-offenders, compared to the overall population of offenders. If such recruiters can in fact be linked to disproportionate numbers of co-offenders, then it would be necessary to look at a far larger number of cases, preferably at the population level. Thus, our first task is to complement the existing literature with a rich empirical exposition of recruitment.

Second, is recruitment more likely to exist in certain types of offenses, but not others? Both Reiss and Farrington (1991) and McGloin and Nguyen (2012) have shown that "instigation" can be conditional on crime type. The Colorado study focused on incarcerated individuals and found what we would define as "recruitment specialization," manifested in certain skills, which predicted recruitment more than other predictors. However, it might be the case that McGloin and Nguyen's (2012) subgroup is unique, given the fact that these are incarcerated participants. Tumminello et al. (2013), who studied a large set of Swedish suspects, did find that while a large group of suspects can be described as "generalists," there are non-trivial patterns of specialization across the age and gender of the suspects. However, Tumminello et al. (2013) and Sarnecki (2001) did not look specifically at recruiters. We intend to examine the question of specialization in recruitment more closely on our wider offender population who are not within their prison sentence.

Finally, should we find similar patterns and distributions in the data as earlier studies - and we hypothesize that we will-then the stack of evidence demands a more robust conceptual framework. The body of research on recruitment is primarily descriptive. Differential association, social exchange theory, and the taxonomic theories suggest that there are 
differences between recruits and recruiters and that there may be narrative differences between recruiters and recruits. These, however, do not amount to a ground-breaking theory that can characterize and predict recruitment - or even cooffending - more formally. We will suggest that meme theory (Dawkins, 1976) is a palatable framework for this endeavor.

\section{Methods}

\subsection{Data Sources}

We analyzed population data from the Sacramento City Police Department (SPD) between, 2004 and 2011. The city of Sacramento is located in the center of the state of California, halfway between San Francisco and Lake Tahoe. The city is home to more than 475,000 people, and the greater metropolitan area has a population of 2.5 million people (United States Census Bureau, 2012). In 2012, the metropolitan population was comprised of $15 \%$ African Americans and $28 \%$ Hispanics (UC Census Bureau, 2013). Collectively, $83 \%$ of the residents were high school graduates, but less than $50 \%$ owned their homes (Bureau of Labor Statistics, 2013). In terms of crime (FBI, 2013), there were about 7.1 homicides, 242 robberies, and 812 burglaries per 100,000 residents.

Starting in 2004, the SPD began using a digitized database of all types of police reports (except for traffic accidents). All patrol vehicles and field officers were equipped with computers, while all reports were processed (uploaded) by the officer in the field - a direct input into the database. There were 80,245 individuals who were involved in 128,629 unique criminal cases in which an arrest was "registered" in this system. The richness of the dataset enabled us to conduct a comprehensive analysis of all contacts with offenders known in the SPD for a comparatively long period of time $(8 \text { years })^{1}$.

\subsection{Measurement}

\subsubsection{Recruiters}

To be operationally defined as a "recruiter," an offender must have had a prolific criminal background (Farrington and van Mastrigt, 2011; McGloin and Nguyen, 2012; Reiss and Farrington, 1991), which we defined as having at least three prior arrests. A higher threshold used in previous studies (e.g., van Mastrigt and Farrington, 2011) excluded too many potential offenders. It is unlikely that a California offender would have been arrested for a major crime three or more times and not be incarcerated for a long period of time, for example, under the "three strikes you're out" law (see Chen, 2008).

Second, a recruiter must have had at least three neural links to other individual co-offenders. We assumed that recruiters who "specialize" in persuading others to commit crimes with/for them were likely to reach out to as many co-offenders as possible, to maximize the gain of these recruitment processes. This criterion limits the population of interest even further, as co-arrests are not common. To illustrate how rare "official co-offending" is, that is, as measured by arrest records, consider that only $12 \%$ of the entire Sacramento population were co-arrested, and within this sub-group a more limited group was arrested with three or more co-arrestees. Therefore, these links, measured by at least three co-arrests, are logical indications of recruitment patterns (van Mastrigt and Farrington, 2011), but they also limit the number of potential individuals we could analyze. We acknowledge that intelligence reports may prove more useful in the assessment of these co-offending patterns (see Linton, 2016). Likewise, self-reported instigations (see McGloin and Rowan, 2015) can provide a richer picture of recruitments, as researchers are then able to add additional variables. However, these intelligence databases were not made available to us, nor did we have access to self-reported criminal behavior at the population level.

Lastly, given the scope of the database, we were limited to offenders who were arrested in the geographical boundaries of the city of Sacramento and offended between 2004 and 2011. There may be older recruiters who began co-offending prior to this period. There may also be a great deal of migration to neighboring or possibly more remote abodes. Nevertheless, the data for these cases were not made available to us. For a general discussion on data tracking, see Wain and Ariel (2014).

\subsubsection{Recruits}

We defined recruits as co-offenders who were younger when compared to the recruiters, or those who experienced their first arrest with a recruiter (i.e., had never been arrested before). If the nature of the relationship ought to be somewhat

\footnotetext{
${ }^{1}$ As correctly argued by McGloin, Sullivan, Piquero, and Bacon (2008:179), "official record data [do] not contain many theoretically relevant predictors of co-offending and co-offenders. Future research should attempt to collect a wide range of data to examine what constellation of individual, environmental, and situational variables are related to cooffending and co-offender patterns." We return to these observations when discussing the limitations of our study.
} 
similar to a pupil-mentor affiliation, then recruiters are likely to recruit newcomers and young co-offenders. Therefore, only co-offending relationships in which the recruit was a less experienced offender/was younger than the recruiter were included in the analysis. Excluding co-offenders who are experienced and/or older than the recruiter made it possible to exclude organized gangs, as such pupil-mentor relationships are possible but not necessary conditions for co-offending in organized settings. We did not limit the age gap between the recruiter and the recruited offender as we found no theoretical basis for any particular criterion; for instance, a persuasive 28-year-old prolific offender may have the capacity to convince an 18-year-old but also a 27 -year-old first-time offender to do a "job" with him. Likewise, having a rigid criterion (e.g., more than 3 years apart), would limit our capacity to look at recruitment patterns in juveniles.

\subsection{Analytical Procedure}

\subsubsection{Data Structuring}

To access and modify the official database, we used structured query language (SQL) to extract data from SPD databases. Once the data were exported, one row was given for each suspect for each charge $(\mathrm{n}=251,285)$, with columns for suspect's ID, crime type, date of birth, and additional variables. For a suspect with ten identified charges per case, there would be ten rows of data. Each arrestee who had had three arrests would be considered a "prolific offender," and the person would be flagged for the next stage of the analysis. Then, for each prolific offender, we searched cases where s/he was co-arrested. The co-arrest was a marker of co-offending. We then limited the cooffending relationships to those in which the co-arrestees were younger and less experienced than the prolific offenders. Finally, we limited the subsample to prolific offenders further to those who have had at least three such co-offending relationships.

\subsubsection{Network Analysis}

The study of network representations of physical, biological, and social phenomena is on the rise (American National Research Council, 2010). Social network analysis is increasingly implemented in the study of criminal behaviors, particularly in a "big data" environment. Formally, we used open-source software (Gephi) to create cartographic network maps. This software allowed us to graphically encapsulate the relationship between recruiters and recruits. In practice, we computed the number of links that each actor, that is, recruiter-has had with other actors (co-offenders). We looked at the "betweenness" of these actors (Freeman, 1977; Newman, 2005), which is a measure of the centrality of the actor in a network: visually, this means that each actor and the degree of betweenness are measured by their relative value from within the graph. Every individual is represented by a circle, or node, and the size of each circle represents the number of connections, or edges, that each node has with other nodes. Thus, the more an individual cooffends - or has more recruits, as in our study - the larger the node. Each group of recruiter-recruits, or module, is identified with a unique color. The largest node in each map also details the size of the module (proportional to the crime-category size).

Figure 1 provides a close view of seven discrete networks randomly selected from the dataset, with 16 recruiters and 51 recruits, to illustrate what recruiter-recruit networks look like. Note the dark blue cluster in the upper left corner, indicating a group of offenders with three recruiters and eleven shared recruits, while the yellow cluster in the bottom right of Fig. 1 shares similar characteristics.

\subsubsection{Recruitment Patterns in Discrete Crime Categories}

We categorized the relationships according to the discrete crime categories because tendencies to co-offend vary across crime types (Piquero, Farrington, and Blumstein, 2007), and we suspected that the same will take place in recruitment relationships (see McGloin and Nguyen, 2012). The SPD used 23 high-order categories of crime, and this classification allowed us to observe in which crime-groups recruitment is more likely to occur. Based on previous research using interviews with juveniles (McGloin and Nguyen, 2012), there should be more frequent recruitment attempts in specific crime groups, for instance, narcotics (Desroches, 2007), but less in violence (Conway and McCord, 2002) or arson (Hickle and Roe-Sepowitz, 2010).

\section{Results}

\subsection{Descriptive Statistics}

Our Sacramento population data include records from eight consecutive years (2004-2011) on 80,245 individuals who were involved in 128,629 unique criminal cases in which an arrest was made. These individuals were arrested for 251,285 distinct criminal charges. We identified 112,963 instances of solo arrests (88\%) and 12,319 cases where there were two persons arrested for the same offense (10\%). Two percent of the sample was arrested in groups of three or more for the same offense, and 928 persons were arrested ten times or more.

Overall, 1,092 offenders fit our definition of recruiters and 4,157 were identified as recruits. This is a similar proportion 
identified previously by Reiss and Farrington (1991) - about $1.4 \%$ of the entire population. For recruiters, the mean number of arrests was $6.37(\mathrm{SD}=3.9)$ and the mean number of co-offenders was $5.44(\mathrm{SD}=2.6)$, while recruits were arrested on average 4 times $(\mathrm{SD}=3.7)$ and had $3.64(\mathrm{SD}=2.6)$ co-offenders. More importantly, most of the recruiters' co-offenders are indeed younger - about 3.4 years' difference $(\mathrm{SD}=1.5)$ - and less experienced $(\mathrm{M}=2.1 ; \mathrm{SD}=1.2)$. We also found that the mean age at first arrest for the recruits was relatively older than expected $(\mathrm{M}=22.8 ; \mathrm{SD}=3.5)$. These and other frequencies are presented in Table 1.

Table 1. Recruiters and recruits in Sacramento, (total population $n=80,245,2004-2011$ )

\begin{tabular}{lcc}
\hline & Recruiters & Recruits \\
\hline $\mathrm{N}$ & 1,092 & 4,157 \\
Mean number of total arrests & $6.37(3.90)$ & $4.03(3.70)$ \\
Mean number of solo arrests & $6.99(5.59)$ & $2.39(2.09)$ \\
Mean number of co-offenders & $5.44(2.64)$ & $3.64(2.56)$ \\
Mean number of recruits per recruiter & $4.60(0.80)$ & -- \\
Mean number of younger co-offenders per recruiter & $4.01(1.66)$ & -- \\
Mean number of first-time co-offenders per recruiter & $2.11(1.22)$ & -- \\
Mean age difference between recruiter and recruit & $3.38(1.40)$ & -- \\
Mean age of recruiter at time of arrest with recruit & $26.13(4.89)$ & $22.78(3.54)$ \\
Mean age of recruit at time of first arrest & -- & \\
\hline
\end{tabular}

Looking more closely at these descriptive findings, it appears that there are two discrete types of recruits. On the one hand, there are prolific offenders recruited by recruiters and, on the other hand, there are first-time offenders recruited by the recruiters. The first type of recruits is comprised of mature offenders, and they are responsible for a significant proportion of all crimes in Sacramento. These prolific offenders are disproportionately involved in all arrests in Sacramento: $32 \%$ of all robbery arrest cases, $24 \%$ of all robberies, and $23 \%$ of all homicides include one of the individuals from the 4,157 recruits. The second group of recruits is comprised of younger individuals whose arrest with the recruiter marks their first encounter with the criminal justice system. Many recruits were first-time offenders when they were arrested with the recruiters, and recruiters have had on average two first-time offenders with whom they were arrested (Table 1), which tends to suggest that while experienced offenders commit crimes with other experienced offenders (group 1), there is another identifiable type of recruits that have only begun their criminal behavior with the recruiter (group 2).

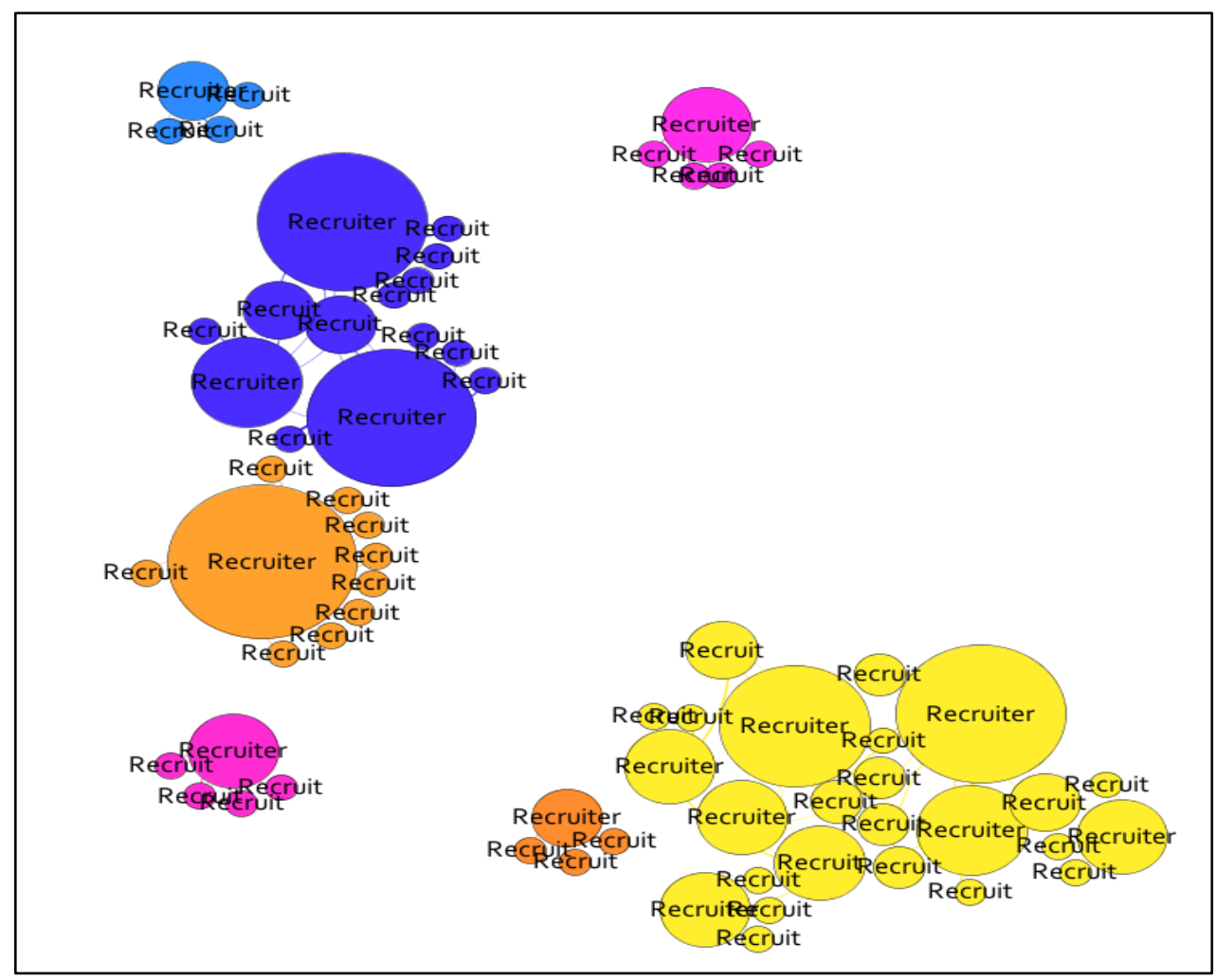

Figure 1. Close-up view of recruiters-recruits networks 


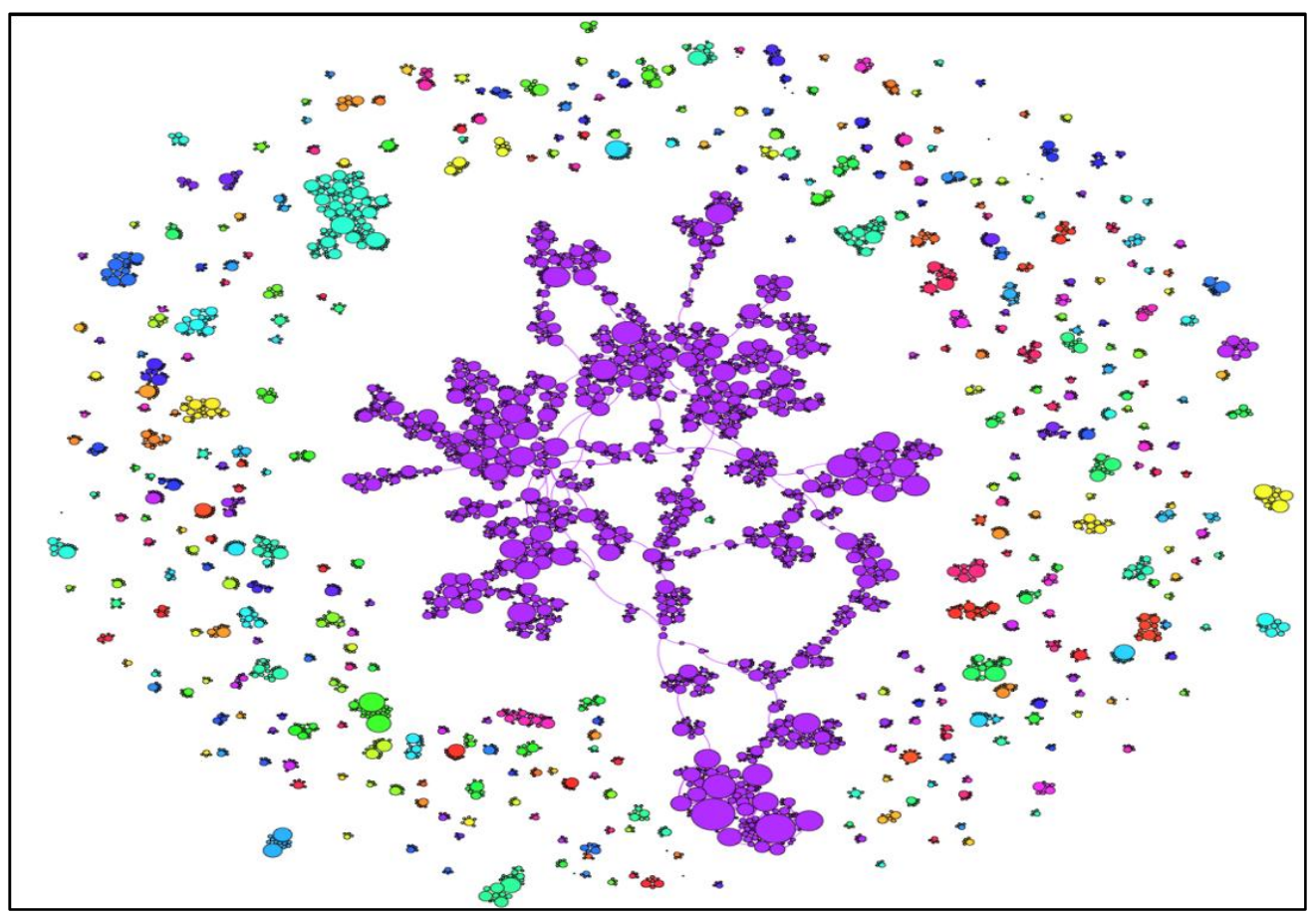

Figure 2. Network map of all 1,092 recruiters and 4,157 recruits (all crime categories)

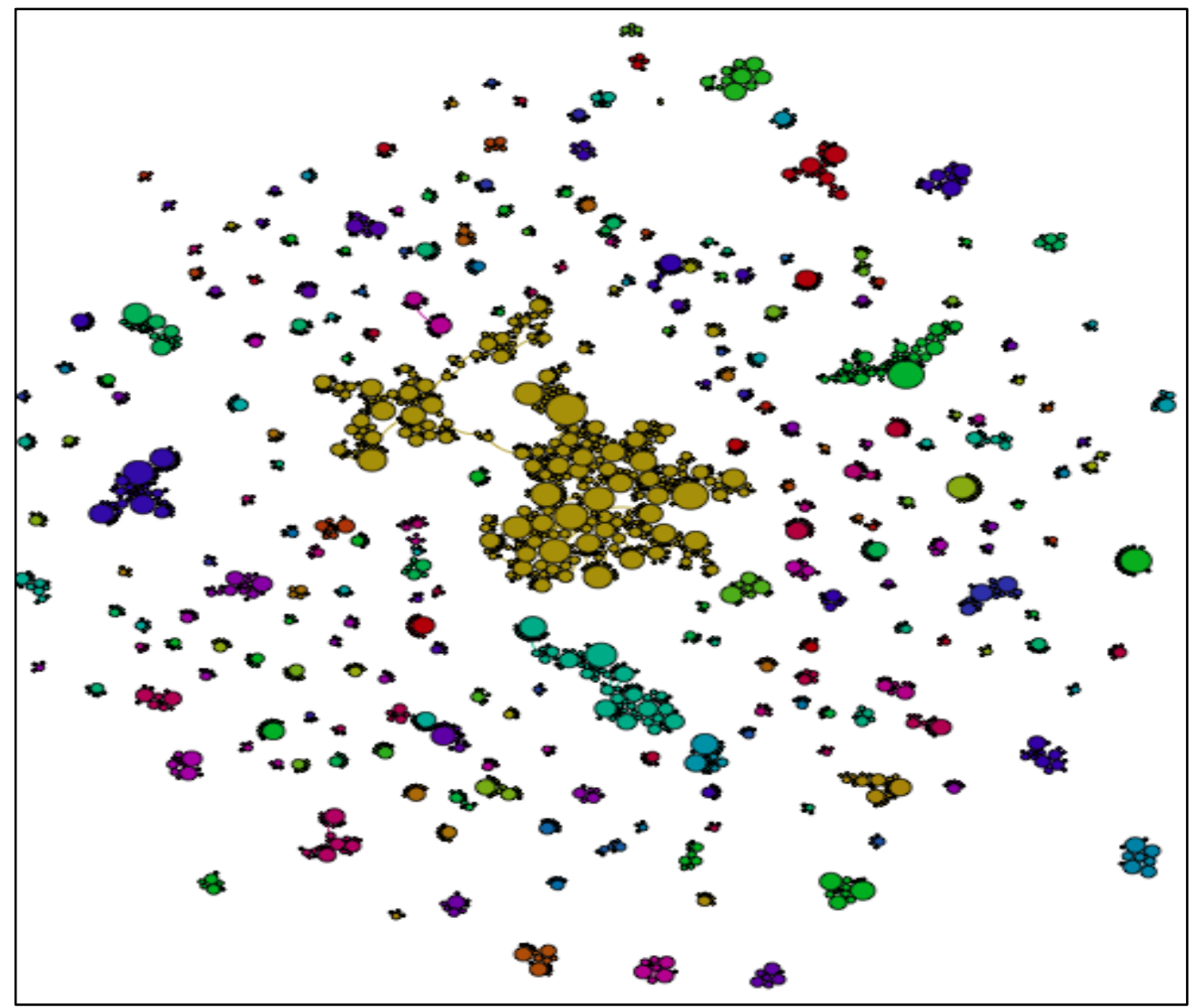

Figure 3. Network map of burglary recruiters and associated co-offenders ( $22 \%$ of all nodes occur in the central cluster (goldenrod)) 


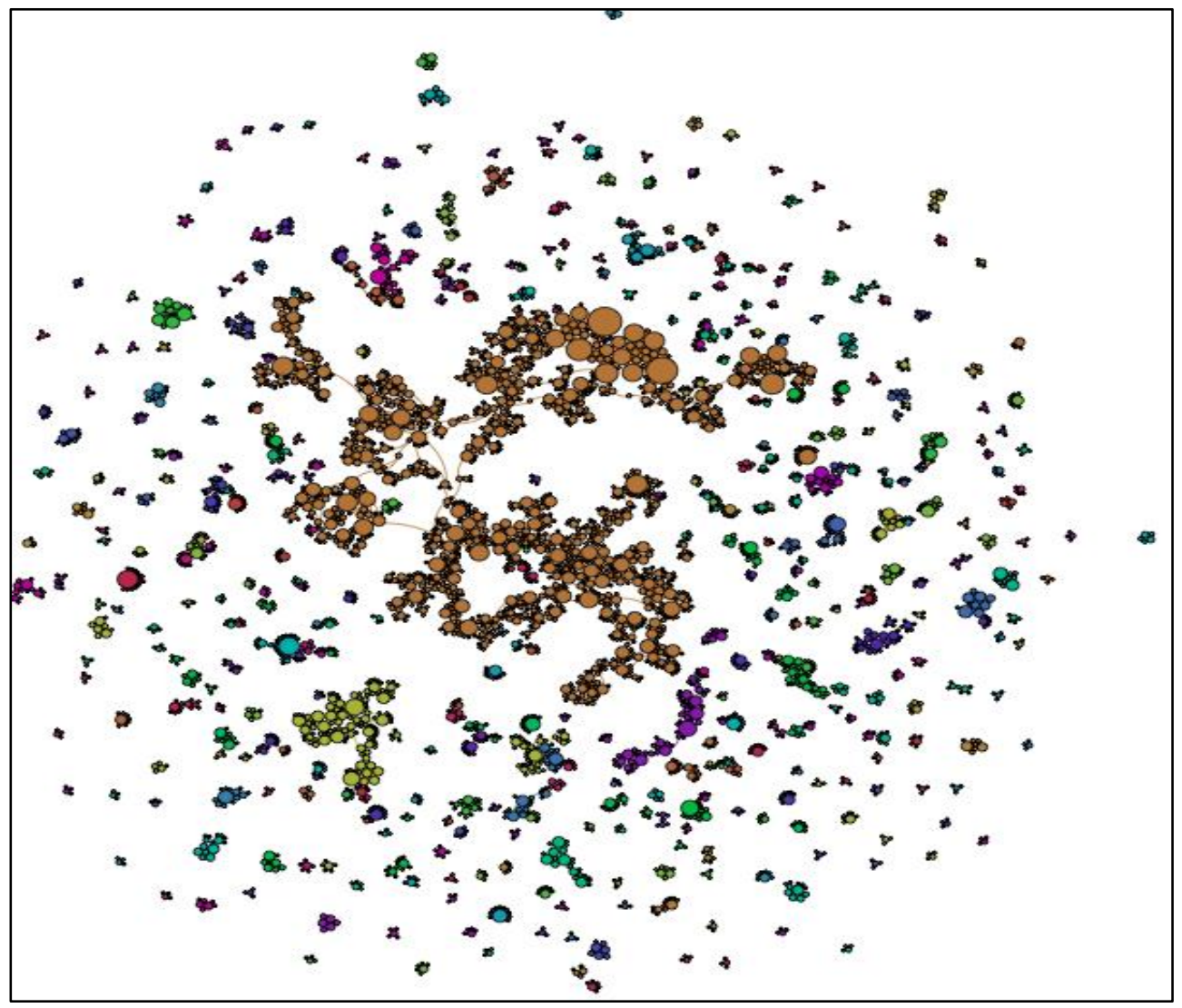

Figure 4. Network map of narcotics recruiters and associated co-offenders ( $32 \%$ of all nodes occur in the central cluster (copper dots))

\subsection{Social NetworkMaps}

Figure 2 below depicts all the network connections between the 1,092 recruiters and their 4,157 recruits. The colors denote that the nodes are connected by at least one shared node, while the size of each node depends on the number of connections (edges) it has with other nodes. Therefore, the larger the node, the more connections that individual has with other offenders. One interesting finding is that a large proportion of these offenders in Sacramento are associated with another. For instance, the central cluster of individuals denoted by purple in Fig. 2 contains $40.19 \%$ of all individuals shown on the map; or, the arrest records indicate that 2 of 5 Sacramento offenders in this sample are linked to one another through criminal activity. Figure 3 then provides a visual illustration of all known burglary networks, while Fig. 4 looks at known narcotic networks. As shown, 22\% of all burglary recruiters and recruits are associated with one another, while $32 \%$ of all narcotics nodes are linked to one another.

\subsection{Patterns of Recruitment within Crime Categories}

Table 2 details the results when the point of reference is the arrest as the unit of analysis, with recruitment patterns within discrete crime categories. The table lists the distribution of crime categories $(n=23)$, along with the number of arrests $(n=182,692)$, number of cases involving a single offender arrested only $(n=167,185)$, and the number of arrests involving a recruiter and the recruited. We found that recruiters were found in $6 \%$ of the arrest cases $(\mathrm{n}=10,967)$ in the eight years of arrest data. Table 2 then lists the percentage of all recruiters and all recruits involved in each crime category. Notice that the percentages do not result in $100 \%$, as recruiters and recruits could have been arrested multiple times. The top-ranked cells in each category are in bold for ease of reference.

From Table 2, the top arrest categories involving recruiters are municipal codes (15\%), school offenses (13\%), robberies $(13 \%)$, burglaries $(10 \%)$, and property crimes $(9 \%)$. However, when focusing on the representation of recruiters and recruits' proportions in each category (that is, how many of these individuals were arrested for certain offenses), we find that recruiters committed most of these crimes. We found that nearly $75 \%$ of recruiters were arrested for narcotics $(58 \%$ of recruits), $59 \%$ were arrested for probation violations (36\% of recruits), and more than a third were arrested for burglary, larceny, or assault. Between $27 \%$ and $28 \%$ of the recruits were arrested for assaults, burglaries, and larceny. Importantly, while the top five categories for both the recruiter and the recruit are generally similar, the relative 
difference in the extent to which each group is active, that is, the qualified difference between the recruits and the recruiters is large. For instance, recruiters are involved in narcotics $30 \%$ more than recruits.

Table 2. Sacramento recruitment data with the arrest as the unit of analysis: 23 crime categories (2004-2011)

\begin{tabular}{|c|c|c|c|c|c|}
\hline Crime Category & $\mathrm{N}$ arrests & $\begin{array}{c}\text { arrests } \\
\text { involving a } \\
\text { single offender } \\
\end{array}$ & $\begin{array}{c}\mathbf{N} \text { arrests involving } \\
\text { a recruiter } \\
\text { (proportions) } \\
\end{array}$ & $\begin{array}{c}\text { \% of all recruiters } \\
(n=1,092) \text { involved in } \\
\text { crime category }\end{array}$ & $\begin{array}{c}\text { \% of } \text { all recruits } \\
(n=4,157) \text { involved in } \\
\text { crime category }\end{array}$ \\
\hline Alcohol & 1,376 & 1,194 & $50(3.6 \%)$ & $3.90 \%$ & $2.60 \%$ \\
\hline Arson & 255 & 218 & $7(2.8 \%)$ & $0.60 \%$ & $0.60 \%$ \\
\hline Assault & 24,460 & 22,676 & $660(2.7 \%)$ & $37.60 \%$ & $28.40 \%$ \\
\hline Auto theft & 4,466 & 4,052 & $322(7.2 \%)$ & $19.40 \%$ & $13.90 \%$ \\
\hline Burglary & 7,377 & 5,884 & $730(9.9 \%)$ & $36.00 \%$ & $26.70 \%$ \\
\hline Homicide & 386 & 303 & $24(6.2 \%)$ & $2.10 \%$ & $2.10 \%$ \\
\hline Judicial & 11,377 & 10,900 & $580(5.1 \%)$ & $35.80 \%$ & $24.20 \%$ \\
\hline Juvenile & 183 & 180 & $13(7.1 \%)$ & $1.00 \%$ & $1.30 \%$ \\
\hline Larceny & 18,649 & 16,535 & $690(3.7 \%)$ & $37.30 \%$ & $28.40 \%$ \\
\hline Municipal code & 2,246 & 2,021 & $328(14.6 \%)$ & $9.80 \%$ & $6.20 \%$ \\
\hline Narcotics & 36,704 & 32,952 & $2,826(7.7 \%)$ & $74.70 \%$ & $57.50 \%$ \\
\hline Persons crime & 4,361 & 4,191 & $170(3.9 \%)$ & $13.10 \%$ & $8.40 \%$ \\
\hline Probation violation & 23,847 & 22,763 & $2,027(8.5 \%)$ & $58.80 \%$ & $35.60 \%$ \\
\hline Property crime & 4,919 & 4,195 & $462(9.4 \%)$ & $30.30 \%$ & $20.30 \%$ \\
\hline Public order & 6,284 & 5,504 & $484(7.7 \%)$ & $27.10 \%$ & $19.30 \%$ \\
\hline Robbery & 3,265 & 2,464 & $421(12.9 \%)$ & $26.90 \%$ & $19.50 \%$ \\
\hline School offense & 503 & 362 & $67(13.3 \%)$ & $4.60 \%$ & $3.40 \%$ \\
\hline Sex assault & 1,422 & 1,380 & $38(2.7 \%)$ & $2.80 \%$ & $1.70 \%$ \\
\hline Traffic & 17,087 & 16,980 & $325(1.9 \%)$ & $23.20 \%$ & $14.80 \%$ \\
\hline Vandalism & 3,729 & 3,455 & $138(3.7 \%)$ & $10.40 \%$ & $8.20 \%$ \\
\hline Vice & 2,402 & 2,118 & $139(5.8 \%)$ & $7.10 \%$ & $5.60 \%$ \\
\hline Weapons & 7,394 & 6,858 & $466(6.3 \%)$ & $31.40 \%$ & $19.60 \%$ \\
\hline TOTALS/AVG. & 182,692 & 167,185 & $10,967(6.0 \%)$ & $22.45 \%$ & $15.83 \%$ \\
\hline
\end{tabular}

Table 3. Sacramento recruitment data with the offender as the unit of analysis (2004-2011), N=80,245 offenders

\begin{tabular}{|c|c|c|c|c|c|}
\hline Crime Category & $\begin{array}{l}\text { N Recruiters } \\
\text { Arrested }\end{array}$ & $\begin{array}{l}\text { N Recruits } \\
\text { Arrested }\end{array}$ & $\begin{array}{c}\text { Mean N Recruits per } \\
\text { Recruiter }\end{array}$ & $\begin{array}{l}\text { Mean Age of } \\
\text { Recruit }\end{array}$ & $\begin{array}{c}\text { Mean Age } \\
\text { Diffe rence betwe en } \\
\text { Recruiter and } \\
\text { Recruit } \\
\end{array}$ \\
\hline Alcohol & 66 & 356 & 6.59 & 24.20 & 2.35 \\
\hline Arson & 8 & 50 & 6.25 & 19.85 & 2.10 \\
\hline Assault & 598 & 2,397 & 5.32 & 22.68 & 3.57 \\
\hline Auto theft & 27 & 146 & 5.67 & 27.25 & 5.07 \\
\hline Burglary & 482 & 2,003 & 5.40 & 19.59 & 2.81 \\
\hline Homicide & 48 & 183 & 5.60 & 24.36 & 4.03 \\
\hline Judicial & 454 & 2,006 & 5.55 & 22.87 & 3.36 \\
\hline Juvenile & 13 & 84 & 6.54 & 15.15 & 0.68 \\
\hline Larceny & 520 & 2,211 & 5.39 & 20.36 & 2.37 \\
\hline Municipal code & 145 & 616 & 6.02 & 23.23 & 3.10 \\
\hline Narcotics & 1,040 & 3,848 & 5.12 & 22.30 & 3.15 \\
\hline Persons crime & 182 & 851 & 5.53 & 27.47 & 5.74 \\
\hline Probation violation & 735 & 2,927 & 5.10 & 21.42 & 3.76 \\
\hline Property crime & 395 & 1,757 & 5.51 & 26.22 & 5.46 \\
\hline Public order & 470 & 1,837 & 6.19 & 30.34 & 5.34 \\
\hline Robbery & 377 & 1,599 & 5.64 & 24.30 & 3.91 \\
\hline School offense & 94 & 362 & 6.67 & 16.48 & 0.25 \\
\hline Sex assault & 37 & 216 & 6.03 & 22.90 & 3.47 \\
\hline Vandalism & 160 & 693 & 5.42 & 20.83 & 2.95 \\
\hline Vice & 89 & 422 & 5.49 & 24.71 & 3.63 \\
\hline Weapons & 408 & 1,891 & 5.40 & 21.78 & 3.93 \\
\hline AVG. & & & 5.73 & 22.78 & 3.38 \\
\hline (S.D.) & & & $(0.47)$ & (3.54) & (1.40) \\
\hline
\end{tabular}

3.4 Recruitment Networks - Group Dimensions and Relationships between Recruiters and Recruits

Next, we looked at the criminal involvement of recruiters and recruits when the unit of analysis is the individual offender. This means that for each crime category, we captured the criminal records of the recruiters and the recruits and illustrated the number of arrests that these offenders have accumulated in their criminal career. We then measured the number of recruits per recruiter in each crime category, the mean age of the recruit, and the mean age difference between the recruiter and the recruit (Table 3 ). 
This approach first and foremost revealed for which offenses there are more recruiters and recruits than others. For example, we found that nearly all recruiters and recruits (95\% and $93 \%$, respectively), were arrested at some point in their lives for a drug offense. More than two thirds of the recruiters and the recruits $(67 \%$ and $70 \%$, respectively) were arrested for probation violations, about half were arrested for larceny, and $60 \%$ for assaults. Perhaps surprisingly, fewer than $5 \%$ of the recruiters and the recruits were arrested for juvenile or automobile thefts, as one would suspect that in such crime categories the mentor-mentee relationship would flourish.

However, while these findings speak to the volume of recruiters and recruiters, it does not speak to the intensity of recruitment; the top five categories for recruitment were alcohol offenses, arson, juvenile, public orders, and school offenses, but not narcotics or assaults, for instance. Each of the recruiters in these top categories recruited on average about 6.5 recruits while all other categories recruited about 5.5 recruits. The overall mean number of recruits per recruiter $(M=5.7 ; \mathrm{SD}=0.47)$ is far greater than the threshold we have anticipated (three).

Finally, we note that the largest age differences between the recruiters and recruits were in against-person crimes, property crimes, public orders, and auto thefts (all around 5 years). The oldest mean recruit age was for public orders, against-person crimes, and auto thefts, each above 27 -years-old. The youngest mean recruit age was found in arson, burglary, school offenses, and juvenile offenses, each at younger than 20-years-old. These patterns are shown in Table 3.

\subsection{Crime-Specific Recruiters}

In terms of the "professional relationship" between recruits and recruiters-beyond the age criterion we reviewed in Table 3-another way of looking at the process is recruitment in specific categories of crimes. Recruiters may be "good" at organizing co-offenders to unique criminal behaviors, that is, recruitment may be crime-specific and therefore each node would attract co-offenders in the same crime category. This form of recruitment is potentially more prevalent when the type of crime requires specialized skills (like art robberies) and when the offense is prone to be committed in groups (unlike traffic crime, for instance). Table 4 thus presents recruitment patterns that are crime-specific. The highest values are darkened for ease of reference.

Table 4. Crime-specific recruitments: 23 categories of crime

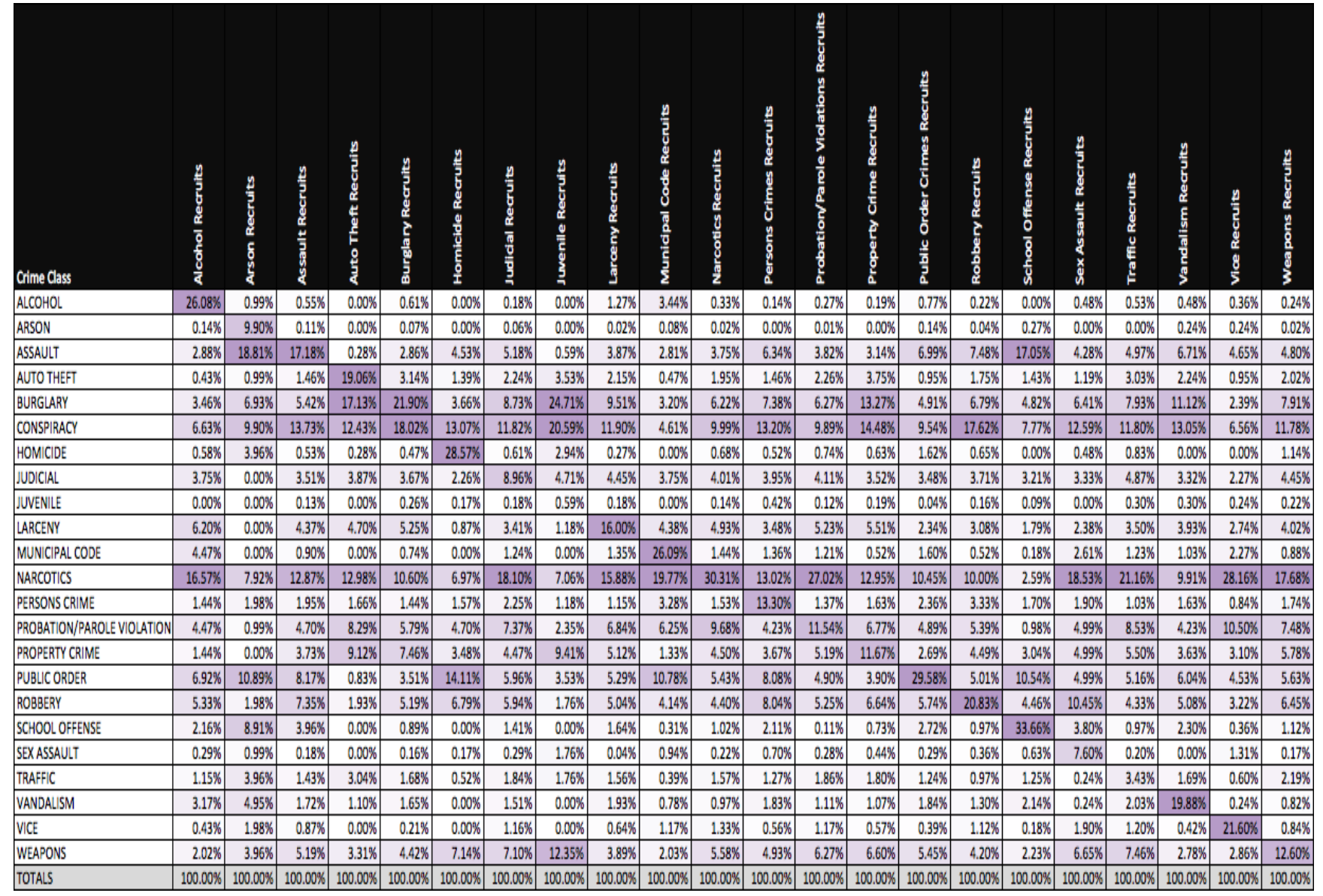


We found discernable specialization patterns. When recruited by a recruiter who tends toward burglary, for instance, the recruit would tend toward burglary as well. When those who were recruited by a burglary recruiter were arrested, $21.09 \%$ of those cases involved a burglary charge, the highest in the column. For the most part, the rest of the table follows the same general pattern, with just a few notable exceptions due to burglary and narcotics charges. In terms of burglary charges, we found that among those recruited by a recruiter specializing in juvenile offenses, $24.71 \%$ of all cases involved burglary, followed by, $20.59 \%$ and $12.35 \%$ in conspiracy and weapons charges, respectively. Those who are recruited by a recruiter who tend toward probation and parole violations are almost twice as likely to be arrested for a narcotic charge as a probation or parole violation. Those who are recruited by a recruiter who specializes in property crimes are more likely to be arrested for burglary, conspiracy, and narcotics than for property crimes. Yet in terms of narcotics, the banding is even more pronounced. Among those who are recruited by recruiters specializing in narcotics, judicial, probation, or parole violations, sex assaults, traffic, vice, and weapons, narcotics charges are the primary activity for which they are arrested. In crimes involving alcohol, assault, auto theft, burglary, larceny, municipal codes, against-person crimes, property crimes, public order, and robbery, narcotics-related activity accounts for the second or third highest level of activity for which they are arrested. Note that the horizontal pattern on the conspiracy row is merely indicative of the fact that the table as a whole is calculated from those who co-offend.

\section{Discussion}

McGloin and Nguyen (2011:17) recently commented that "empirical investigations that test the supposed profile of recruiters are rare. There are conceptual reasons to believe that some individuals, who are older than their less experienced accomplices, are high rate offenders and who rotate through several accomplice groups, are those who are systematically more prone to instigate group crime." The idea that some offenders are "ideas men" and that they pull in other offenders to commit crimes for/with them is only recently becoming a topic of systematic exploration (e.g., McGloin and Thomas, 2016; McGloin and Nguyen, 2012; McGloin and Rowan, 2015; van Mastrigt and Farrington, 2011), though the theoretical conceptualization has been around for some time (Reiss, 1986, 1988; Reiss and Farrington, 1991). Our findings add to this growing line of research both conceptually and empirically, with populationlevel arrest data from a large Californian city.

Our data clearly singles out a small group of "power few" offenders who tend to act in criminal networks (Sherman, 2007; see also Wilkinson, 2006). We focused on these small networks in which two or more individuals were arrested for the same offense, and then focused specifically on the recruiter-recruit relationship. The way we have operationalized these "recruiters" and "recruits" has limited the number of potential persons of interest to a selective portion of all arrested individuals; these recruiters represent only $1.36 \%$ of the entire population across eight years of data. This is comparable to van Mastrigt and Farrington's (2011) and Reiss and Farrington's (1991) figures. Yet their contribution to criminal behavior is quite substantial: they seem to be "ideas men" who facilitate or "make" other people — often younger or less experienced — commit disproportionately more crime for/with them. The recruits— $5 \%$ of the population - committed more than 17,000 crimes. The finding that most of the recruits are significantly younger and less experienced makes these recruiters particularly interesting, despite being a relatively small group of offenders. We also believe that the arrest records represent a limited view of these co-offending patterns, a point to which we will address below.

Before that, however, we note that applying a network analysis framework to this relatively new criminal recruitment literature provides a new way of looking at criminal behavior. This is specifically the case when looking at unique categories of crime in which recruitment is more likely to occur. This analytical approach teaches us not only how prolific recruiters and their recruits organize themselves when offending, but also the types of subgroup networks within crime types. This type of analysis was not available when earlier scholars were considering the possibility that some offenders are likely to instigate others into criminal activities (Breckinridge and Abbott, 1912; Cohen, 1955; Shaw and McKay, 1942; Piquero, Farrington, and Blumstein, 2003; Reiss, 1986, 1988; Reiss and Farrington, 1991; Shaw and Moore, 1931; Warr, 1996).

\subsection{Contextualizing Recruitment Processes More Broadly: Meme Theory}

A central element in virtually all crime theories is that, based on different points of departure, they assume that criminal behavior is transmitted between individuals. Learning theories and differential association (Sutherland, 1947), social disorganization theories (Shaw and McKay, 1942), strain theories (Merton, 1938; Agnew, 1992), culture conflicts (Lewin, 1948), social bonding theories (see review in Gardner and Shoemaker, 1989) - they all share a common feature embedded within them, that the "crime idea" is carried between the various actors. The central question that social network analysis is trying to answer is how can we study this transmission? "Anthropologists," Sperber (2000:163) reminds us, "have always considered culture as that which is transmitted in a human group." Sociologists, nevertheless, have offered a limited set of explanations for how these transmissions take place. One prominent approach that has 
gained popularity in recent years is observing the network as the unit of analysis. As reviewed earlier, Wasserman and Faust (1997:20) suggested that "a social network comprises a limited number of actors and the relations among the actors." This methodological approach then enables us to describe the links between the various actors, or nodes, especially in more complicated and long-term criminal networks (Sarnecki, 1986, 2001). However, we think the stack of evidence on social networks, especially the latest research on recruitment patterns within these networks, lends itself to another perspective and can more accurately fit within meme theory.

Though not without critique (Edmonds, 2005; Kull, 2000; Sperber, 2000), in the last 40 years, several papers have dealt with memes as a concept (e.g., Dawkins, 1976, 1982; Brodie, 1996; Lynch, 1996, Blackmore, 1999). There are different ways to consider memes; however, one common characteristic of memes is that they are "units of imitation" (Weimer, Priesterjahn, and Goebels, 2005:48; see also Tomasello, Kruger, and Ratner, 1993). The evolutionary biologist Richard Dawkins (1976) coined this term as a concept for discussing evolutionary principles when explaining the spread of ideas and cultural phenomena. Dawkins $(1976,1999)$ contested that information affects the behavior of its host and is portable to other hosts. There is, accordingly, a self-replicating unit of transmission. The examples offered in the literature so far include a broad range of ideas and phenomena, such as chain letters, Facebook comments, tweets, melodies, ethnic prejudices, religious ideas, YouTube clips, fashion, as well as criminal ideas (Cohen et al., 1995:211)2.

"Crime ideas" can be contextualized as memes because they $d o$ spread within cultures, subcultures, and particular social networks. They have to spread to survive against other completing ideas (e.g., not breaking the law), otherwise they would fade out. The "meme pool" is wide and deep, and only ideas that prove more effective at replicating and surviving are selected (see Sidebottom, 2009). Particularly in the case of crime memes, we know people transmit these ideas from person to person, from group to group, and from generation to generation, because criminality and delinquency are as old as any human behavior (Hitchens, 2003). As contested by Ekblom (1999:30), "[i]n the crime context, examples of memes are criminal values and subcultures, methods of offending, or of prevention, and the requisite designs, tools and equipment developed by either side. 'Good' memes survive, and are reproduced through cultural transmission on the offenders' or the preventers' side, as appropriate; 'bad' ones are soon forgotten." By extension, we see that crime ideas must sometimes be deemed as "good ideas" by some members of society, or else the technical skills and moral justifications for committing a crime could not be reproduced and evolve over time. Thus, their spread in society, much like other cultural artifacts or ideas, depends on the capacity of these criminal ideas to be transmitted and consequently replicated as preferred, as attractive and efficient entities within a culture (see Surette, 2015) — or at the very least within subcultures and criminal networks.

Of course, crime is not just a transferrable concept, but a learned skill (Akers et al., 1979; Akers and Jensen, 2005; Bandura, 1963, 1977), an enterprise, and a social event. To survive against competing ideas, crime must be represented as efficient. Committing crime will be considered a "good idea" to imitate, in and by itself, only if it can be shown to be successful in attaining the aims behind committing the crime (see Merton, 1938). Otherwise, the virtue of a selfreplicating unit of transmission is not met and the reproductive nature of "ideas" will cause the ideas to become extinct (on the minimal conditions for replications, see Sperber, 2000:170). Yet crime ideas are never extinct. They do replicate. They could evolve and mature, or dilute and become minimized, but crimes, as ideas, have survived over time and space. "Crime memes"- or "Memeplexes," which are comprised of a complex group of memes that replicate together and co-adapt - are indeed transmitted, and the proof is in their continuous perseverance against "legitimate memes."

Using meme theory seems to elegantly define the power of the idea of the crime, especially in network environments. Instigation is largely a generative concept (see McGloin and Nguyen, 2012). It starts off with one actor in the network and then moves through the links to other actors in the wider criminal network. The crime idea spreads from person to person within that network, with varying degrees of success, depending on the attributes of both the links and the actors, and especially based on the type of relationship that exists between the "transmitting actor" and the "recipient actor." Lynch (2008) refers to this process as "thought contagion." The process affects the types of behaviors that are deemed efficient and their relationship with the individuals they inhabit. Because offenders-like all humans - are efficient copiers of memes and consequently behavior, the criminal meme evolves and transmits across the social network. Particularly in American subcultures, countercultures, and underground rings - which are as popular as ever (FBI, 2016) - crime ideas are attractive to millions of Americans every year (Ferrell and Ilan, 2013; Manning, 2013).

Given these broader remarks, we can move on to show just how recruiters are transmitters of the crime meme within the Sacramento population. These actors have certain attributes that enable them to transfer to their recruits the notion that "crime pays" (Tremblay and Morselli, 2000) and that committing a criminal offense is a preferred possibility. Recruiters

\footnotetext{
${ }^{2}$ It seems that computer sciences and information technology research have seen more applications of this approach, yet the general framework can be used to explain any process of transmitting ideas between people.
} 
carry the idea through as imitators, and are influential not only because they transmit the crime meme themselves (see below), but also because the crime meme is retained within the recruit even after the carrier- the recruiter - is no longer around. Our finding that most recruits have continued to be arrested long after the initial arrest with the recruiter (Table 1), strongly supports the idea that the meme idea was "embedded" within these recruits, and — as importantly — that the recruits were then co-arrested with others as well (Figs. 2-4), suggests that the crime meme imitation continued to spread.

Another indication that memes are carried through the recruiters is that a large proportion of recruiters and recruits in Sacramento are associated with one another. A similar pattern was shown by Sarnecki (2001) for co-offending networks more broadly. For instance, the central cluster of actors denoted by purple in Fig. 2 contains $40 \%$ of all actors. As shown, 2 of 5 Sacramento offenders in this sample are linked to one another through criminal activity. Figure 4 shows that a fifth of all burglary recruiters and recruits are associated with one another, while $32 \%$ of all narcotics recruits and recruiters are linked to one another. Given our operational definition of recruits - first-time offenders and younger than their recruiters - having such a strong link between the actors suggests spreading a "good idea" about committing crime (see McGloin and Nguyen, 2012:480, Warr, 1996).

The attributes of the links in terms of crime categories is also indicative of meme reproduction. This suggests that not only is the idea of crime transmitted, but it takes place within a bounded specialization (see also Tumminello et al., 2013). We found that nearly $75 \%$ of recruiters and $58 \%$ of recruits were arrested for narcotics, and that nearly all recruiters and recruits ( $95 \%$ and $93 \%$, respectively), were arrested at some point in their lives for drug offenses (see Desroches, 2007). Drug dealing is particularly susceptible to recruitment, because it requires not only a network of potential clients but - more crucially - middle managers who must instigate the idea in a person that selling drugs is profitable. Similarly, we found specialization patterns that would suggest that teaching unique skills and mentoring has taken place, which would then carry through in future criminal behavior as well. For example, when recruited by a recruiter who has a propensity for burglary, recruits would develop a propensity towards burglary as well: we have shown that when individuals were recruited by a burglary recruiter, more than a fifth committed burglary. We found that among those recruited by a recruiter specializing in juvenile offenses, $24.71 \%$ of all cases involve burglary, followed by $20.59 \%$ and $12.35 \%$ in conspiracy and weapons charges, respectively. In crimes involving alcohol, assault, auto theft, burglary, larceny, municipal codes, against-person crimes, property crimes, public order, and robbery, narcotics-related activity accounts for the second or third highest level of activity in which they are arrested.

The major exception to these findings is recruitment in the case of juvenile delinquency, which, according to our records, experienced very little instigation. This was somewhat surprising from a theoretical perspective (see McGloin and Nguyen, 2012), however, commonsensical from a design perspective. The nature of our data limits our capacity to see recruitment patterns beyond arrest records, and it therefore suffers from low external validity (Maxfield, Weiler, and Widom, 2000, however, $c f$. Hindelang, Hirschi, and Weis, 1979). Juvenile delinquency could be more concealed than we previously believed (see Wikström et al., 2012:12). There may be instigation and imitation (i.e., memes passing through) more frequently and more intensely in juvenile networks than criminal records show, albeit for less serious offenses. Officers might be reluctant to document the arrest in the case of juveniles to not label them as "offenders." Furthermore, McGloin et al. (2008:179) have already commented that "official record data did not contain many theoretically relevant predictors of co-offending and co-offenders." They then accurately suggested that "future research should attempt to collect a wide range of data to examine what constellation of individual, environmental, and situational variables are related to co-offending and co-offender pattern" (ibid). This is therefore the case for juvenile recruiters and recruits as well: data triangulation is crucial for explaining criminal networks, recruitment, and crime memes.

\subsection{Policy Implications}

According to Reiss (1988), high frequency offenders are "active recruiters to delinquent groups and can be important targets for law enforcement." The practical implications of the existence of such an individual has a direct bearing on how law enforcement agencies seek to efficiently manage crime, specifically how law enforcement agencies seek to deter crime from occurring in the first place. Indeed, Sherman (1992) posited the idea that a greater level of research and experimentation on recruiters would lead to a greater level of efficiency on the part of the police. Akers (2009), Clarke and Eck (2005), and Ratcliffe (2008) concurred and suggested that removing the most important member of a group would have a larger negative effect on the intensity of the criminal messages received by the group members. Put differently: these offender recruiters might be targeted for special treatment. McGloin and colleagues (2008:177) alluded to the fact that "value exists in having a sense of the general trend of co-offender stability as well as in distinguishing people who evidence stability from those who do not. For example, dismantling one co-offending network would likely not impact individual rates of co-offending if the stability of co-offenders is negligible and/or if replacement/substitution effects exists, as is often the case with drug dealing" (Blumstein, 1993). Lantz and Hutchison 
(2015:663-64) add to this by stating that "conversely, arresting the most important offenders (i.e., the instigators) may significantly decrease the offending rates of other offenders within the co-offending group, even without the arrest of additional offenders." Thus, at least from a targeting perspective (Sherman, 2013), "it can be readily assembled in any police agency with computer systems linking individual rap sheets to arrest reports naming co-arrestees. Rank ordering of all rap sheet subjects by total numbers of co-offenders could reveal enormous disparity, with a small number of offenders being linked to over half of all other offenders" (Sherman, 1992:186). Yet Reiss, Sherman, and McGloin's remarks have remained quite unchallenged.

Interestingly enough, even our body of evidence on targeting prolific offenders more broadly (let alone recruiters) is incredibly thin and weak (see, for example, Bland and Ariel, 2015). To the best of our knowledge, there have been no randomized controlled trials designed to test particular prevention interventions "against" recidivist offenders, outside the criminal justice system, probation circles, or bespoke interventions. Unlike place-based initiatives (Braga et al., 2012), our evidence based on deterring prolific offenders is very limited. Even at the network level, 'pulling levers' programs and focused deterrence initiatives (Braga and Weisburd, 2012) have been assessed under non-controlled conditions, which diminish the causal estimates of the findings. However, we still sense that future research as well as policy should target these recruiters for two prominent reasons. First, specific deterrence might reduce their own criminal behavior, and at the same time potentially prevent them from instigating crime by others. Second, there may be a ripple effect (Papachristos et al., 2015), whereby the deterrence message might be spilled over to the recruits as well, thus affecting their behavior.

\subsection{Research Implications}

The next step, after the identification has been made, is for law enforcement to effectively deal with those who infect, or are infected, with the crime meme. Dealing with the infected using the focused deterrence strategy may be appealing to law enforcement because of its familiarity, but the question must be asked: is it effective? To answer that question, the gold standard of testing must be utilized, that of the randomized control trial (Cook, Campbell and Day, 1979; see also the discussion in Ariel, 2016:359, cf. Ariel et al, 2017). A randomized control trial would target the recruiters in hopes of affecting the offending rate of the recruiters and also that of the recruits, and thus the crime rate of the entire crime network.

\subsection{A Final Word about the Age-crime Curve}

As we noted above, the group of recruits who were younger when they were arrested with the recruiter are of particular interest to us. We have found that recruiters have been arrested, on average, with two first-time offenders, which suggests that while experienced offenders commit crimes with other experienced offenders, there is an identifiable type of recruits who have just started their criminal behavior with the recruiter. Future research should focus more closely on these individuals and investigate further the socio-demographic characteristics of these recruits, as these data points were unavailable to us. McGloin et al. (2008) have in fact already started this type of investigation with a sample of young offenders, but we suspect that such explorations would be important for mature offenders as well.

Furthermore, consistent with theory is the mean age difference between recruiters and recruits: more than three years, which we believe is quite substantial, especially in early adult life (e.g., a 20-year-old "hanging out" with a 24-yearold). This age difference is particularly noticeable in serious offenses - homicide, property crime, and against-persons' crime, as well as auto theft-with more than a 5-year gap between recruiters and recruits (Table 3 ). In juvenile and school offenses, there was virtually no age difference, which makes sense given the nature of the offense. These trends seem to make sense as youths often associate within their age group in relatively petty offenses, but they lay out an important pattern in recruitment networks: recruiters recruit individuals who are significantly younger than them to commit serious crimes with them, while recruiters recruit individuals who are only slightly younger than them to commit less serious offenses with them. These findings are consistent with the co-offending literature on the link between severity of crime and age (Felson, 2003; Conway and McCord, 2002; Sarnecki, 2001; Warr, 2002; Zimring, 1981), yet we add a more granular distinction in the context of recruitment.

At the same time, despite this potential dichotomy between recruit types that may be dependent on age, we have found that the overall mean age of recruits is actually much older than we anticipated-25 years - which is well above the crime-age-curve (Fabio, Tu, Loeber, and Cohen, 2011; Farrington, 1986; Sweeten, Piquero, and Steinberg, 2013). One would expect that impressionable juveniles would be more susceptible to these recruitment patterns, which should sit well with bio-psychological explanations of criminal behavior (Agnew, 2006; Moffitt, 1993). However, these are relatively mature offenders, almost in the part of the age curve that is dedicated to persistent and long-lasting offenders, or for the common offenders who desist out of crime in their late 20's. This is likely to be explained by the fact that these are, overall, prolific offenders with seven prior arrests, often significantly more. Still, despite the somewhat older age of these recruits, they are nevertheless significantly younger than their recruiters, which tends to suggest that 
recruitment —unlike general crime patterns - is a social phenomenon that does not necessarily happen in same-age peer groups but rather in hierarchical social relationships, not too dissimilar from tutor-pupil relationships. We are therefore tempted to suggest that crime committed in groups, particularly in recruiter-recruit relationships, could foster a new way of thinking about the age-crime curve. However, more research is needed in this area, which is outside the scope of our present study.

\subsection{Additional Limitations}

For the most part, people in Sacramento are arrested just once (66\%), and $88 \%$ are arrested alone. This would suggest that crime is a "one off, single man's game," but this contradicts previous claims that there is "substantial evidence that offending, particularly youth offending, is a group phenomenon" (Andresen and Felson, 2012:813; however, $c f$. Carrington, 2002). As we reviewed earlier, a relatively mature and developed body of empirical research addressed and reconfirmed the relationship between deviant social networks and crime (Gottfredson and Hirschi, 1990; Hirschi, 1969; McGloin and Nguyen, 2012). However, because the precise patterns of co-offending and recruitment into crime within criminal networks are relatively unclear to us (van Mastrigt and Farrington, 2009), the fact that so many offenders are arrested alone despite the criminal network within which they are likely to operate, introduces more questions for future research.

Furthermore, the number of elements used to identify a recruiter were few. This limiting factor was inherent in using only arrest data to attempt to identify recruiters. While not limiting in this context, perhaps future research in this area would do well do include offender data, such as geographical data, including addresses of the offenders, locations of arrest, and proximity to crime hotspots. Other data, such as school records and the inclusion of data to indicate links other than co-offending, would also be useful, including gang connections, neighborhood links, and persons who were listed on the same report as others even if they were not arrested with those, non-crime type reports, traffic accidents, casualty reports, and so on. Any one of these link factors would increase the possible number of connections between offenders and, perhaps more importantly, provide a method for determining an individuals' likelihood of becoming a recruiter or recruit. The goal of future research on this topic should include the ramifications of those previously listed data elements being used as well as regression models to develop algorithms that might indicate one's propensity of becoming a recruiter or a recruit.

Despite the recent rise in interest in this subject, it remains unclear how one can influence others to commit crimes, or how a particular person is capable of exerting pressure on his/her peers to get involved in illegal behavior (Andresen and Felson, 2012). Throughout the paper, we were careful not to make an empirical claim as to whether these recruiters "make" these recruits commit crime with them, or for them. This merit further investigation with a different set of data. Yet, it is important to consider how these recruiters are understood in the wider context of social networks, for which survey studies with recruits could be enlightening.

\section{Conclusion}

Co-arrest records allow scholars to investigate co-offending patterns. Using social network analysis to explore how "crime ideas" are transmitted, a sub-set of prolific offenders who act like recruiters can be identified. These influential nodes in Sacramento were responsible for $6 \%$ of all arrest cases and a disproportionate number of younger and less experienced offenders to be recruited into crime. There is evidence to suggest that recruitment specialization in specific crime categories, as well as a wider age differential between recruiters and their recruits in against-persons rather than property crime categories. One way to contextualize the findings may be within Dawkin's (1976) meme theory: crime ideas can be seen as units of imitation, and under certain conditions they are subsequently replicated, reproduced, and evolve.

\section{References}

Abrutyn, S., \& Mueller, A. S. (2014). Reconsidering Durkheim's assessment of Tarde: Formalizing a Tardian theory of imitation, contagion, and suicide suggestion. In Sociological Forum,29(3), 698-719. https://doi.org/10.1111/socf.12110

Agnew, R. (1992). Foundation for a general strain theory of crime and delinquency. Criminology, 30(1), 47-88. https://doi.org/10.1111/j.1745-9125.1992.tb01093.x

Agnew, R. (2006). General strain theory: Current status and directions for further research. Taking Stock: The Status of Criminological Theory, 15, 101-123.

Akers, R. L. (2011). Social learning and social structure: A general theory of crime and deviance. Transaction Publishers New Brunswick, NJ.

Akers, R. L., \& Jensen, G. F. (2005). Social Learning Theory and crime: A progress report. Advances in Criminological 
Theory, 15, 1-61.

Akers, R. L., Krohn, M. D., Lanza-Kaduce, L., \& Radosevich, M. (1979). Social learning and deviant behavior: A specific test of a general theory. American Sociological Review, 44(4), 636-655. https://doi.org/10.2307/2094592

Alarid, L. F., Burton, V. S., \& Cullen, F. T. (2000). Gender and crime among felony offenders: Assessing the generality of social control and differential association theories. Journal of Research in Crime and Delinquency, 37(2), 171199. https://doi.org/10.1177/0022427800037002002

Allbritton, D. W. (1995). When metaphors function as schemas: Some cognitive effects of conceptual metaphors. Metaphor and Symbolic Activity, 10(1),33-46. https://doi.org/10.1207/s15327868ms1001_4

Andresen, M. A., \& Felson, M. (2012). Co-offending and the diversification of crime types. International Journal of Offender Therapy and Comparative Criminology, 56(5), 811-829. https://doi.org/10.1177/0306624X11407154

Ariel, B. (2016). 'Increasing Cooperation With The Police Using Body Worn Cameras'. Police Quarterly, 19(3): 326362

Ariel, B., Sutherland, A., Henstock, D., Young, J., and Sosinski, G. (2017). The Deterrence Spectrum: Explaining Why Police Body-Worn Cameras 'Work' Or 'Backfire' In Aggressive Police-Public Encounters. Policing: A Journal of Policy and Practice. https://doi.org/10.1093/police/paw051

Bandura, A. (1977). Self-efficacy: toward a unifying theory of behavioral change. Psychological review, 84(2), 191. https://doi.org/10.1037/0033-295X.84.2.191

Bland, M. and Ariel, B. (2015). 'Targeting Escalation in Reported Domestic Abuse: Evidence From 36,000 Callouts'. International Criminal Justice Review, 25(1): 30-53

Blumenthal, M. D., Kahn, R. L., Andrews, F. M., \& Head, K. B. (1972). Justifying violence: Attitudes of American men. Institute for Social Research, the University of Michigan.

Braga, A. A., \& Weisburd, D. L. (2011). The effects of focused deterrence strategies on crime: A systematic review and meta-analysis of the empirical evidence. Journal of Research in Crime and Delinquency, 0022427811419368.

Braga, A. A., \& Weisburd, D. L. (2012). The effects of focused deterrence strategies on crime: A systematic review and meta-analysis of the empirical evidence. Journal of Research in Crime and Delinquency,49(3), 323-358. https://doi.org/10.1177/0022427811419368

Braga, A. A., \& Weisburd, D. L. (2012). The effects of 'pulling levers' focused deterrence strategies on crime. Campbell Systematic Reviews, 6. https://doi.org/10.4073/csr.2012.6

Breckinridge, S. P., \& Abbott, E. (1912). The Delinquent Child and the Home. New York: Charities Publication Committee.

Budd, J. (2008). Crime, interrupted: Treating violent crime as a disease. Retrieved 15 November 2012 from http://www.economist.com/node/ 12574177

Bureau of Labor Statistics. (2013). Local area unemployment statistics, annual average rankings. http://www.bls.gov/lau/lastrk11.htm.

Carrington, P. J. (2002). Group crime in Canada. Canadian Journal of Criminology, 44(3), 277-316.

Carrington, P. J. (2009). Co - offending and the development of the delinquent career. Criminology, 47(4), 1295-1329. https://doi.org/10.1111/j.1745-9125.2009.00176.x

Chen, E. Y. (2008). Impacts of "three strikes and you're out" on crime trends in California and throughout the United States. Journal of Contemporary Criminal Justice, 24(4), 345-370. https://doi.org/10.1177/1043986208319456

Clarke, R. V., and Eck, J. E. (2005). Crime analysis for problem solvers in 60 small steps. Washington, DC: U.S. Department of Justice, Office of Community Oriented Policing Services.

Cloward, R. A., \& Ohlin, L. E. (2013). Delinquency and opportunity: A study of delinquent gangs (Vol. 6). Routledge.

Cohen, A. K. (1955). Delinquent boys: The subculture of the gang. London: Colher-Macmillan.

Cohen, L., \& Felson, M. (2009). Routine Activities Theory. In Akers, L., Sellers, C., (eds). Criminological Theories 3545.

Conway, K. P., \& McCord, J. (2002). A longitudinal examination of the relation between co-offending with violent accomplices and violent crime. Aggressive Behavior, 28(2), 97-108. https://doi.org/10.1002/ab.90011

Cook, T. D., Campbell, D. T., \& Day, A. (1979). Quasi-experimentation: Design \& analysis issues for field 
settings (Vol. 351). Boston: Houghton Mifflin.

Dawkins, R. (1976). The selfish gene. Oxford: Oxford University Press.

Dawkins, R. (1999). "Foreword" to Susan Blackmore The Meme Machine. Oxford: Oxford University Press.

Desroches, F. (2007). Research on upper level drug trafficking: A review. Journal of Drug Issues, 37(4), 827-844. https://doi.org/10.1177/002204260703700405

Dirlam, D. K. (2003). Competing memes analysis. Journal of Memetics-Evolutionary Models of Information Transmission, 7(2), 3-12.

Edmonds, B. (2005). The revealed poverty of the gene-meme analogy - why memetics per se has failed to produce substantive results. Journal of Memetics-Evolutionary Models of Information Transmission, 9(1), 1-4.

Ekblom, P. (1999). Can we make crime prevention adaptive by learning from other evolutionary struggles? Studies on Crime and Crime Prevention, 8, 27-51.

Fabio, A., Tu, L. C., Loeber, R., \& Cohen, J. (2011). Neighborhood socioeconomic disadvantage and the shape of the age-crime curve. Journal Information, 101(S1). https://doi.org/10.2105/ajph.2010.300034

Farrington, D. P. (1986). Age and crime. Crime and Justice, 189-250. https://doi.org/10.1086/449114

FBI. (2013). Uniformed crime reports - California: Offenses known to law enforcement. Criminal Justice Information Services Division, Federal Bureau of Investigation, US Department of Justice. Retrieved from https://ucr.fbi.gov/crime-in-the-u.s/2013/crime-in-the-u.s.-2013/tables/table-8/table-8-statecuts/table_8_offenses_known_to_law_enforcement_california_by_city_2013.xls

Federal Bureau of Investigation (2010). Uniform Crime Reports for Cities in California. Retrieved 17 September 2016 from http://www.fbi.gov/about-us/cjis/ucr/crime-in-the-u.s/2010/crime-in-the-u.s.-2010/tables/table8/10tbl08ca.xls

Federal Bureau of Investigation (2016). Gangs. Retrieved 16 September 2016 from https://www.fbi.gov/investigate/violent-crime/gangs

Felson, M. (2009). The natural history of extended co-offending. Trends in Organized Crime, 12(2), 159-165. https://doi.org/10.1007/s12117-008-9056-7

Ferrell, J., \& Ilan, J. (2013). Crime, culture, and everyday life. In C. Hale, K. Hayward, A. Wahidin (eds.) Criminology. Oxford: Oxford University Press, 368-384 . https://doi.org/10.1093/he/9780199691296.003.0018

Freeman, L. (1977). A set of measures of centrality based on betweenness. Sociometry, 40, 35-41. https://doi.org/10.2307/3033543

Gardner, L., \& Shoemaker, D. J. (1989). Social bonding and delinquency. The Sociological Quarterly, 30(3), 481-500. https://doi.org/10.1111/j.1533-8525.1989.tb01532.x

Goffman, E. (1967). Interaction ritual: Essays on face-to-face behavior. New Brunswick: Aldine Transaction Publishers.

Gottfredson, M. R., \& Hirschi, T. (1990) A general theory of crime. California: Stanford University Press.

Grasmick, H. G., \& Bursik, J. R. J. (1990). Conscience, significant others, and rational choice: Extending the deterrence model. Law and Society Review, 837-861. https://doi.org/10.2307/3053861

Hickle, K. E., \& Roe - Sepowitz, D. E. (2010). Female juvenile arsonists: An exploratory look at characteristics and solo and group arson offences.Legal and Criminological Psychology,15(2), 385-399. https://doi.org/10.1348/135532509X473913

Hindelang, M. J., Hirschi, T., \& Weis, J. G. (1979). Correlates of delinquency: The illusion of discrepancy between selfreport and official measures. American Sociological Review, 995-1014. https://doi.org/10.2307/2094722

Hirschi, T. (1969) Causes of delinquency. London: Transaction Publishers.

Hitchens, P. (2003). A brief history of crime: The decline of order, justice and liberty in England. Atlantic.

Hochstetler, A. (2001). Opportunities and decisions: Interactional dynamics in robbery and burglary groups. Criminology, 39(3), 737-764. https://doi.org/10.1111/j.1745-9125.2001.tb00939.x

Horney, J., Osgood, D. W., \& Marshall, I. H. (1995). Criminal careers in the short-term: Intra-individual variability in crime and its relation to local life circumstances. American Sociological Review, 655-673. https://doi.org/10.2307/2096316 
Katz, J. (2008). Seductions of crime: Moral and sensual attractions in doing evil. Basic Books.

Kennedy, D. M. (2009). Gangs and public policy. Criminology \& Public Policy, 8(4), 711-716. https://doi.org/10.1111/j.1745-9133.2009.00587.x

Klein, M. W., \& Crawford, L. Y. (1967). Groups, gangs, and cohesiveness. Journal of Research in Crime and Delinquency, 4(1), 63-75. https://doi.org/10.1177/002242786700400105

Kull, K. (2000). Copy versus translate, meme versus sign: Development of biological textuality. European Journal for Semiotic Studies, 12(1), 101-120.

Lantz, B., \& Hutchison, R. (2015). Co-Offender Ties and the Criminal Career The Relationship between Co-Offender Group Structure and the Individual Offender. Journal of Research in Crime and Delinquency, 0022427815576754.

Lewin, K. (1948). Resolving social conflicts: Selected papers on group dynamics. Oxford: Harper \& Brothers.

Linton, B. (2016). 'Targeting Criminal Recruiters in London.' Presented at the 9th International Conference on Evidence-Based Policing (12 July 2016, Cambridge, UK).

Lynch, A. (2008). Thought contagion: How belief spreads through society. Basic Books.

Lyons, R. (2011). The spread of evidence-poor medicine via flawed social-network analysis. Statistics, Politics, and Policy, 2(1), 1-16. https://doi.org/10.2202/2151-7509.1024

Manning, P. (2013). Drugs and popular culture. Devon: Willian Publishing.

Mastrigt, S. B., \& Farrington, D. P. (2010) Prevalence and characteristics of co-offending recruiters. Justice Quarterly, 28(2), 325-359. https://doi.org/10.1080/07418825.2010.482535

Matza, D. (1967). Delinquency and drift. Transaction Publishers.

Maxfield, M. G., Weiler, B. L., \& Widom, C. S. (2000). Comparing self-reports and official records of arrests. Journal of Quantitative Criminology, 16(1), 87-110. https://doi.org/10.1023/A:1007577512038

McAndrew, D. (2000). "The Structural Analysis of Criminal Networks." In The Social Psychology of Crime: Groups, Teams and Networks - Offender Profiling Series, edited by David Canter and Laurence Alison. Aldershot, UK: Ashgate

McCarthy, B., \& Hagan, J. (2001). When crime pays: Capital, competence, and criminal success. Social forces, 79(3), 1035-1060. https://doi.org/10.1353/sof.2001.0027

McCord, J., \& Conway, K. P. (2002). Patterns of juvenile delinquency and co-offending. In Crime and social organization (Vol. 10, pp. 15-30). Transaction Publishers New Brunswick, NJ.

McGloin, J. M., \& Kirk, D. S. (2010). Social network analysis. In Handbook of quantitative criminology (pp. 209-224). Springer New York. https://doi.org/10.1007/978-0-387-77650-7_11

Mcgloin, J. M., \& Nguyen, H. (2012). It was my idea: Considering the instigation of co offending. Criminology, 50(2), 463-494. https://doi.org/10.1111/j.1745-9125.2011.00266.x

McGloin, J. M., \& Piquero, A. R. (2010). On the relationship between co-offending network redundancy and offending versatility. Journal of Research in Crime and Delinquency, 47, 63-90. https://doi.org/10.1177/0022427809348905

McGloin, J. M., \& Thomas, K. J. (2016a). Considering the Elements that Inform Perceived Peer Deviance. Journal of Research in Crime and Delinquency. https://doi.org/10.1177/0022427816644944

McGloin, J. M., \& Thomas, K. J. (2016b). Incentives for Collective Deviance: Group Size and Changes in Perceived Risk, Cost, and Reward. Criminology, 54(3), 459-486. https://doi.org/10.1111/1745-9125.12111

McGloin, J., \& Rowan, Z. R. (2015). A threshold model of collective crime. Criminology, 53(3), 484-512. https://doi.org/10.1111/1745-9125.12077

McGloin, J., Sullivan, C. J., Piquero, A. R., \& Bacon, S. (2008). Investigating the stability of co - offending and co offenders among a sample of youthful offenders. Criminology,46(1), 155-188. https://doi.org/10.1111/j.17459125.2008.00105.x

McGuire, J. (2004) Accounting for crime. In McGuire, J., Understanding psychology and crime: Perspectives on theory and action. Maidenhead: Open University Press.

Meltzoff, A., \& Gopnik, A. (1993). The role of imitation in understanding persons and developing a theory of mind. N S. Baron-Cohen et al. (eds.). Understanding other minds. Oxford: Oxford University Press.

Merton, R. K. (1938). Social structure and anomie. American Sociological Review,3(5), 672-682. 
https://doi.org/10.2307/2084686

Moffitt, T. E. (1993). Adolescence-limited and life-course-persistent antisocial behavior: A developmental taxonomy. Psychological Review, 100(4), 674. https://doi.org/10.1037/0033-295X.100.4.674

Nagin, D. S., Solow, R. M., \& Lum, C. (2015). Deterrence, criminal opportunities, and police. Criminology, 53(1), 74100. https://doi.org/10.1111/1745-9125.12057

Newman, M. E. (2005). A measure of betweenness centrality based on random walks. Social Networks, 27(1), 39-54. https://doi.org/10.1016/j.socnet.2004.11.009

Papachristos, A. V., Braga, A. A., Piza, E., \& Grossman, L. S. (2015). The company you keep? The spillover effects of gang membership on individual gunshot victimization in a co - offending network. Criminology, 53(4), 624-649. https://doi.org/10.1111/1745-9125.12091

Piquero, A. R., Farrington, D. P., \& Blumstein, A. (2003). The criminal career paradigm. Crime and justice, 359-506. https://doi.org/10.1086/652234

Piquero, A. R., Farrington, D. P., \& Blumstein, A. (2007). Key issues in criminal career research: New analyses of the Cambridge Study in Delinquent Development. Cambridge University Press. https://doi.org/10.1017/cbo9780511499494

Ratcliffe, J. H. (2008). Intelligence-led policing. Cullompton, Devon, U.K.: Willan.

Reiss Jr, A. J. (1986). Co-offender influences on criminal careers. Criminal careers and career criminals, 2, 121-160.

Reiss Jr, A. J. (1988). Co-offending and criminal careers. Crime and justice, 117-170. https://doi.org/10.1086/449145

Reiss, A. J., \& Farrington, D. P. (1991). Advancing knowledge about co-offending: Results from a prospective longitudinal survey of London males. Journal of Criminal Law and Criminology, 82(2), 360-395. https://doi.org/10.2307/1143811

Rosenau, M. J., Whipple, G. C., Trask, J. W., \& Salmon, W. S. (1921). Preventive medicine and hygiene. New York: D. Appleton and Company.

Rostami, A., \& Mondani, H. (2015). The complexity of crime network data: A case study of its consequences for crime control and the study of networks. PloS one, 10(3). https://doi.org/10.1371/journal.pone.0119309

Sarnecki, J. (1986). Delinquent networks (The National Council for Crime Prevention, Report No. 17). Stockholm, Sweden: Allmänna Förlaget.

Sarnecki, J. (1990). Delinquent networks in Sweden. Journal of Quantitative Criminology, 6(1), 31-50. https://doi.org/10.1007/BF01065288

Sarnecki, J. (2001). Delinquent networks: Youth co-offending in Stockholm. Cambridge University Press. https://doi.org/10.1017/cbo9780511489310

Shaw, C. R., \& McKay, H. D. (1942). Juvenile delinquency and urban areas. Chicago, Ill.

Shaw, C. R., \& Moore, M. E. (1931). The natural history of a delinquent career. Chicago, IL, US: University of Chicago Press. https://doi.org/10.1037/13522-000

Sherman, L. W. (1990). Police crackdowns: Initial and residual deterrence. Crime and Justice, 12, 148. https://doi.org/10.1086/449163

Sherman, L. W. (1992). Attacking crime: Police and crime control. Crime and justice, 15, 159-230.

Sherman, L. W. (2007). The power few: experimental criminology and the reduction of harm. Journal of Experimental Criminology, 3(4), 299-321. https://doi.org/10.1007/s11292-007-9044-y

Sherman, L. W., \& Weisburd, D. (1995). General deterrent effects of police patrol in crime 'hot spots,' a randomised, controlled trial. Justice Quarterly, 12, 625-648. https://doi.org/10.1080/07418829500096221

Sherman, L. W., Gottfredson, D. C., MacKenzie, D. L., Eck, J., Reuter, P., \& Bushway, S. D. (1998). Preventing Crime: What Works, What Doesn't, What's Promising. Research in Brief. National Institute of Justice.

Sidebottom, A. (2009). Crime science and the arms race dynamics of crime prevention. In K. Jaishankar (ed.) International perspectives on crime and justice (pp. 440). Newcastle Upon Tyne: Cambridge Scholar Publishing.

Sperber, D. (2000). An objection to the memetic approach to culture. In R. Aunger (ed.) Darwinizing culture: The status of memetics as a science. Oxford University Press (pp 163-173). 
Surette, R. (2015). Thought bite: A case study of the social construction of a crime and justice concept. Crime, Media, Culture. https://doi.org/10.1177/1741659015588401

Sutherland, E. H. (1947). Principles of Criminology: A Sociological Theory of Criminal Behavior. New York : J. B. Lippincott.

Sweeten, G., Piquero, A. R., \& Steinberg, L. (2013). Age and the explanation of crime, revisited. Journal of Youth and Adolescence, 1-18. https://doi.org/10.1007/s10964-013-9926-4

Tomasello, M., Kruger, A., \& Ratner. H. (1993). Cultural learning. Behavioral and Brain Sciences, 16, 495-552. https://doi.org/10.1017/S0140525X0003123X

Tremblay, P. (1993). Searching for suitable co-offenders. Routine activity and rational choice, 5, 17-36.

Tremblay, P., \& Morselli, C. (2000). Patterns in criminal achievement: Wilson and Abrahamse revisited. Criminology, 38(2), 633-657. https://doi.org/10.1111/j.1745-9125.2000.tb00901.x

US Census Bureau. (2013b). DP05: ACS Demographic and Housing Estimates, American Community Survey 1-Year Estimates (2012).

Van Mastrigt, S. B. (2008). Co-offending: Relationships with age, gender and crime type (Doctoral dissertation, University of Cambridge).

Van Mastrigt, S. B., \& Farrington, D. P. (2011). Prevalence and characteristics of co - offending recruiters. Justice Quarterly, 28(2), 325-359. https://doi.org/10.1080/07418825.2010.482535

Wain, N. and Ariel, B. (2014). 'The Tracking of Police Patrol'. Policing: A Journal of Policy \& Practice, 8(3): 274-283

Walsh, D. (1986). Victim selection procedures among economic criminals: The rational choice perspective. The reasoning criminal: Rational choice perspectives on offending, 39-52. https://doi.org/10.1007/978-1-4613-8625-4_3

Warr, M. (1996). Organization and instigation in delinquent groups. Criminology,34(1), 11-37. https://doi.org/10.1111/j.1745-9125.1996.tb01193.x

Warr, M. (2002). Companions in crime: The social aspects of criminal conduct. Cambridge University Press. https://doi.org/10.1017/cbo9780511803956

Wasserman, S., \& Faust, K. (1994). Social network analysis: Methods and applications (Vol. 8). Cambridge University Press. https://doi.org/10.1017/cbo9780511815478

Watts, D. J., \& Strogatz, S. H. (1998). Nature 393. Original experimental data taken from J. G. White, E. Southgate, J. N. Thompson, and S. Brenner, Phil. Trans. R. Soc. London 314, 1-340 (1986).

Weerman, F. M. (2014). Theories of co-offending. In Encyclopedia of Criminology and Criminal Justice (pp. 51735184). Springer New York. https://doi.org/10.1007/978-1-4614-5690-2_110

Weerman, R. M. (2003). Co-offending as a social exchange. British Journal of Criminology, 43(2), 398-416. https://doi.org/10.1093/bjc/43.2.398

Weimer, A., Priesterjahn, S., \& Goebels, A. (2005). Towards the emergent memetic control of a module robot. Socially Inspired Computing, 45-52.

Wikström, P. O. H., Oberwittler, D., Treiber, K., \& Hardie, B. (2012). Breaking rules: The social and situational dynamics of young people's urban crime. OUP Oxford, 14.

Wilkinson, L. (2006). Revising the Pareto chart. The American Statistician, 60(4), 332-334. https://doi.org/10.1198/000313006X152243

Zimring, F. E. (1981). Kids, groups and crime: Some implications of a well-known secret. The Journal of Criminal Law and Criminology (1973-), 72(3), 867-885. https://doi.org/10.2307/1143269

\section{Copyrights}

Copyright for this article is retained by the author(s), with first publication rights granted to the journal.

This is an open-access article distributed under the terms and conditions of the Creative Commons Attribution license which permits unrestricted use, distribution, and reproduction in any medium, provided the original work is properly cited. 